Review

\title{
Nicotinic-nAChR signaling mediates drug resistance in lung cancer
}

\author{
Wan-Li Cheng1, Kuan-Yuan Chen ${ }^{1,2}$, Kang-Yun Lee ${ }^{1,2,3}$, Po-Hao Feng ${ }^{2,3}$, Sheng-Ming Wu ${ }^{2,3}$ \\ 1. Graduate Institute of Clinical Medicine, College of Medicine, Taipei Medical University, Taipei 11031, Taiwan \\ 2. Division of Pulmonary Medicine, Department of Internal Medicine, Shuang Ho Hospital, Taipei Medical University, New Taipei City 23561, Taiwan \\ 3. Division of Pulmonary Medicine, Department of Internal Medicine, School of Medicine, College of Medicine, Taipei Medical University, Taipei 11031, \\ Taiwan \\ $\square$ Corresponding author: Dr. Sheng-Ming Wu, Division of Pulmonary Medicine, Department of Internal Medicine, School of Medicine, College of Medicine, \\ Taipei Medical University, 250 Wuxing Street, Taipei 11031, Taiwan. Tel: +886 (0)222490088 ext. 8742. E-mail: chitosan@tmu.edu.tw. \\ () The author(s). This is an open access article distributed under the terms of the Creative Commons Attribution License (https://creativecommons.org/licenses/by/4.0/). \\ See http://ivyspring.com/terms for full terms and conditions.
}

Received: 2019.05.05; Accepted: 2019.10.26; Published: 2020.01.01

\begin{abstract}
Lung cancer is the leading cause of cancer death worldwide. Cigarette smoking is the most common risk factor for lung carcinoma; other risks include genetic factors and exposure to radon gas, asbestos, secondhand smoke, and air pollution. Nicotine, the primary addictive constituent of cigarettes, contributes to cancer progression through activation of nicotinic acetylcholine receptors ( $\mathrm{nAChRs)}$, which are membrane ligand-gated ion channels. Activation of nicotine/nAChR signaling is associated with lung cancer risk and drug resistance. We focused on $\mathrm{nAChR}$ pathways activated by nicotine and its downstream signaling involved in regulating apoptotic factors of mitochondria and drug resistance in lung cancer. Increasing evidence suggests that several sirtuins play a critical role in multiple aspects of cancer drug resistance. Thus, understanding the consequences of crosstalk between nicotine/nAChRs and sirtuin signaling pathways in the regulation of drug resistance could be a critical implication for cancer therapy.
\end{abstract}

Key words: nicotinic acetylcholine receptor, drug resistance, mitochondria, sirtuin, lung cancer

\section{Introduction}

Globally, lung cancer is greatest cause of cancer-related deaths. Lung cancer accounts for $14 \%$ and $12 \%$ of all cancers in men and women, respectively, and represents $24.6 \%$ of all cancerrelated deaths [1]. Because of its extraordinary disease burden and international variability in trends of population growth, aging, and smoking behaviors, the global epidemiology of lung cancer requires continual monitoring [2]. Two main subtypes of lung cancer are small-cell lung carcinoma (SCLC) and non-SCLC (NSCLC), respectively accounting for $15 \%$ and $85 \%$ of all lung cancers [3]. NSCLC is further classified into three types: squamous cell carcinoma (SCC), adenocarcinoma, and large-cell carcinoma. SCC is the subtype of NSCLC strongly correlated with cigarette smoking [4]. NSCLC is a complex heterogenous disease with interpatient, intratumor, and inter-/intrametastatic heterogeneity at the subtype level [5]. Both epithelial growth factor receptor (EGFR) mutation and gene amplification status may be notable in determining chemoresistance in NSCLC [6]. Several studies have revealed that never-smokers with lung cancer are more responsive to EGFR-tyrosine kinase inhibitor (EGFR-TKI) therapy than smokers $[7,8]$. Tumor progression and chemoresistance mediated by nicotine and its metabolites have been partly attributed to phosphoinositide 3-kinase (PI3K)/AKT, nuclear

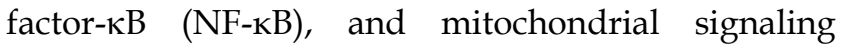
pathways $[7,9,10]$. Therefore, resistance is an inevitable barrier limiting lung cancer therapy effectiveness and reducing enthusiasm, making it today's pervasive challenge for long-term disease control. 


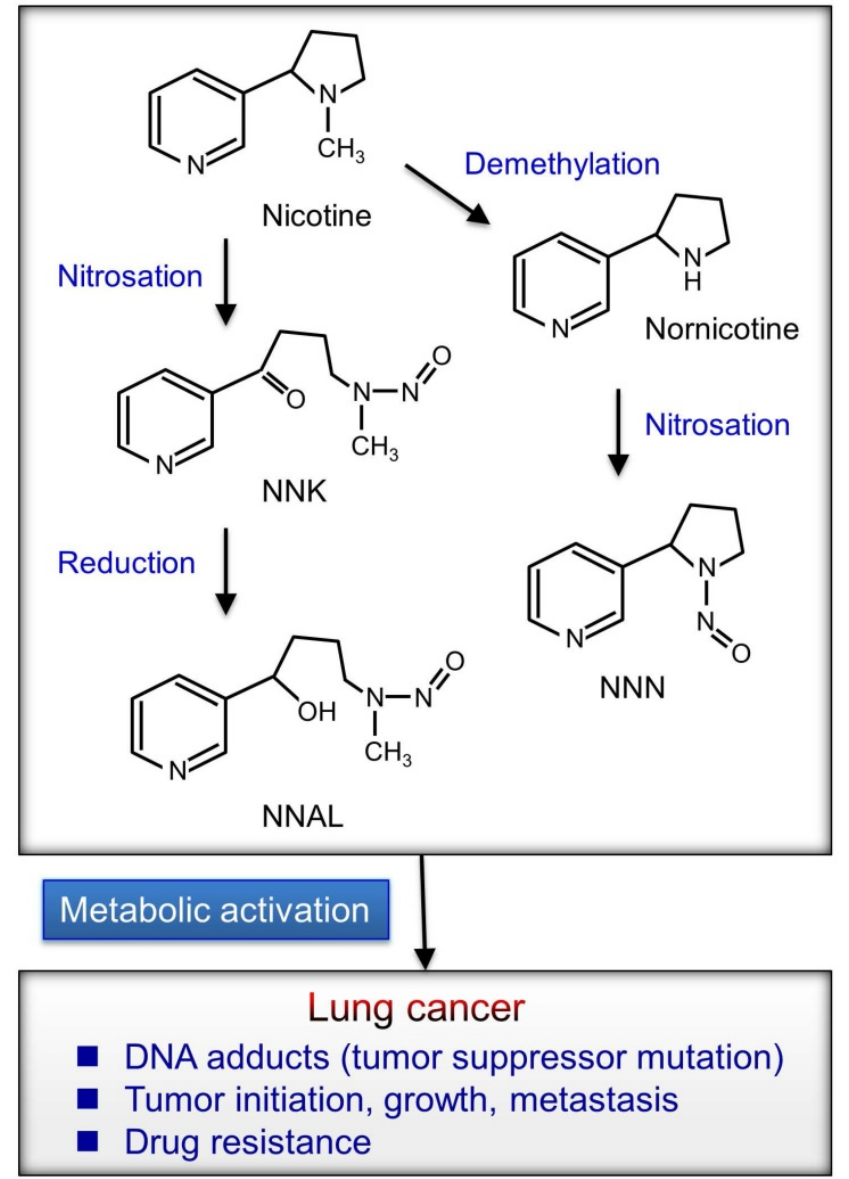

Figure 1: Tobacco-specific $\mathrm{N}$-nitrosamines are formed by the $\mathrm{N}$-nitrosation of nicotine. NNN (N'-nitrosonornicotine) and NNK (4-(metylnitrosamino)1-(3-pyridyl)-1-butanon) are the most potential carcinogens formed by nicotine from cigarette smoke. NNAL (4-(methylnitrosamino)-1-(3-pyridyl)-1-butanol) is a metabolite from the reduction of NNK and total NNAL (NNAL and its glucuronides) in urine and can be used to examine the possible role of $\mathrm{N}$-nitrosamines metabolites in tumor development. Nicotine metabolites carcinogens may induce multiple mutations in critical genes, such as p53, KRAS, p16, and Rb. A permanent mutation occurs in these critical genes that can contribute to activation of the oncogene or blockade of the tumor suppressor gene. Multiple aberrant events can continue to cause cells with abnormal regulation and eventually lung cancer progression.

\section{The biochemical and physiological properties of Nicotine}

Chemicals in cigarette smoke enter the bloodstream and affect the body; thus, smoking causes many diseases including cardiovascular disease, chronic obstructive pulmonary disease (COPD), and lung cancer [11]. Furthermore, nicotine mediates therapeutic resistance, survival and antiapoptosis, and self-renewal of cancer stem cells and modulates many immune properties of cancer [12]. Cigarette smoke contains several carcinogens including benzo $[a]$ pyrene $(\mathrm{BaP})$, polycyclic aromatic hydrocarbons (PAH), nicotine, and nitrosamines [4, 13-15]. Nicotine can promote cancer progression by activating cell-surface receptors, particularly nicotinic acetylcholine receptors (nAChRs) and $\beta$-adrenergic receptors $\quad(\beta-A R) \quad[16-18]$ Tobacco-specific $\mathrm{N}$-nitrosamines is formed by the $\mathrm{N}$-nitrosation of tobacco alkaloids (Fig. 1).

In addition to nicotine, its oncogenic derivatives 4-(methylnitrosamino)-1-(3-pyridyl)-1-butanone (NNK) and N-nitrosonornicotine (NNN), present in tobacco smoke, can activate nAChRs signaling and stimulate multiple cancer-promoting signaling [18, 19]. Total 4-(methylnitrosamino)-1-(3-pyridyl)-1butanol (NNAL), an NNK metabolite, is associated with the lung cancer risk in smokers [20]. These oncogenic metabolites may induce the formation of DNA adducts that leads to mutations of tumor suppressor genes including $\mathrm{Rb}$ and p53 [21]. Nicotine or NNK signaling may contribute to cancer progression [18, 22]. Nicotine was implicated in promoting the self-renewal of stem-like side-population cells from lung cancers. The subpopulation of cancer stem-like cells was implicated in tumor initiation, generation of heterogeneous tumor populations, metastasis, dormancy, and drug resistance [23]. Furthermore, nicotine can inhibit apoptosis induced by opioids, etoposide, cisplatin, and UV irradiation in lung cancer cells [24-26]. Therefore, the activation of nicotine signaling might be associated with drug resistance in lung cancer.

\section{The potential mechanisms of Nicotine on lung carcinogenesis}

Cigarette smoke is associated with an increased risk of all histological types of lung cancer [27]. In general, the lungs retain on average $60 \%-80 \%$ of mainstream smoke particulate matter and $90 \%-100 \%$ of nicotine after cigarette smoke inhalation [28]. The nicotine-derived metabolites including NNK and NNN are potent carcinogens because they bind to a7nAChR [14]. These metabolites and DNA interactions may be the primary cause of lung cancer in smokers. The binding activity of NNK to a7nAChR was 1,300 times greater than that of nicotine [29]. Different nAChR subunits were expressed in NSCLC cells of smokers and nonsmokers [30]. Nicotine present in the plasma of average smokers enhanced $\alpha 7 \mathrm{nAChR}$ expression in human SCC cells [31]. SCC was most strongly associated with cigarette smoke, and adenocarcinoma, the most common lung cancer in never-smokers, has the weakest association. The higher expression of all affected nAChR subunits ( $\alpha 7$, dupa7, a5, and a9) in smokers than in nonsmokers indicated that tobacco components upregulate the expression of a few $\mathrm{nAChR}$ subunit genes in SCC histologic type [32]. The literature has also indicated that only two subunits ( $a 7$ and a5) demonstrated significantly increased expression in SCC with a poor 
prognosis [32]. Furthermore, patients with SCC who died presented significantly higher a7nAChR expression than patients with SCC who survived. For early-stage lung cancers, smoking cessation was associated with a large reduction in mortality risk [33]. a5-nAChR was associated with lung cancer risk and onset, with exposure to a primary cancer etiologic factor (smoking duration and amount), and with the effects of a preventive action (smoking cessation) [34-37]. Chronic exposure to nicotine and derivatives can lead to the upregulation of all nAChRs in smokers. Activation of nicotine-nAChR signaling promotes cancer progression [18]. Upregulation of a7nAChR in lung cancer cells involved in the nicotine-induced tumor progression [38]. Homomeric a7nAChR was implicated as the primary receptor facilitating nicotine- and NNK-mediated cell proliferation [21]. The nicotine- $\mathrm{a} 7 \mathrm{nAChR}$ axis can initiate cell invasion and the epithelial-tomesenchymal transition (EMT) in NSCLC [39]. $n A C h R s, \beta-A R$, and EGFR often coexpress on human lung cancer cells and airway epithelial or endothelial cells that might lead to cancer progression [40]. Nicotine signaling triggers the production of $\beta$-AR ligands, such as adrenaline and noradrenaline, which contribute to the development of lung cancer [21].

Survival analysis of a Cancer Genome Atlas (TCGA) lung cancer dataset demonstrated that high expression of acetylcholine receptors (AChRs) gene family such as CHRM2, CHRM3, CHRNA1, CHRNA2, CHRNA6, CHRNB3, or CHRNE is associated with favorable prognosis in NSCLC adenocarcinoma, but that of CHRNA5/a5nAChR or CHRNA7/a7nAChR is associated with an unfavorable prognosis [41]. Among these proteins, only $\alpha 7 n A C h R$ in the AChR family could affect prognosis in both lung adenocarcinoma and SCC [41]. High CHRNA1 expression is associated with reduced survival in early-stage lung adenocarcinoma after complete resection [42]. Notably, the levels of a7nAChR expression in SCC are higher than those in adenocarcinoma among patients with lung cancer, particularly in smokers [32]. Thus, $a 7 n A C h R$ is a potential target for lung cancer treatment.

Single nucleotide polymorphisms (SNPs) located on chromosome 15q25, which contains the nAChR subunits encoding by the CHRNA5, CHRNA3, and CHRNB4, are associated with lung cancer risk [43]. Lung cancer risk was more than fivefold higher among individuals with both a family history of lung cancer and two copies of high-risk alleles rs8034191 or rs1051730 located in the 15q24-25.1 locus [44]. The change in rs6495309T $>C$ on $15 q 25$ may affect the activity of OCT1 binding to the CHRNA3 promoter, which contributes to CHRNA3 overexpression. These results confirm that $15 q 25$ is a susceptibility region for lung cancer in Chinese individuals [45]. The gene cluster CHRNA5-CHRNA3-CHRNB4 contributes to nicotine dependence risk in African-American and European-American individuals [46]. The missense SNP rs16969968 of CHRNA5 is significantly associated with both nicotine dependence and increased risk of lung cancer [47, 48]. The genome-wide associations of CHRNA3 and CHRNA5 on 15 q25.1 were confirmed in familial SCC [49]. The CHRNA3 polymorphism functions as a genetic modifier of lung adenocarcinoma risk in the Chinese population, particularly in nonsmoking women [50]. CHRNA5 polymorphism is associated with lung adenocarcinoma risk in a population-based series of lung adenocarcinoma patients and healthy controls. An analysis of a family-based series of nonsmoker lung cancer cases and healthy controls indicated a similar trend. In addition, the same D398N variation correlated with CHRNA5 mRNA levels in the lungs of patients with adenocarcinoma [51]. Acetylcholine/ nAChRs and muscarinic acetylcholine receptors can promote cancer cell and lung fibroblasts or myofibroblast proliferation, respectively [52, 53]. Chronic nicotine inhalation or endogenous acetylcholine released in the lungs may play a role in lung disease including COPD and lung cancer. Nicotine/nAChRs stimulates several signaling pathways conferring lung cancer cell survival, as described in the next section (Fig. 2).

\section{The potential mechanisms of Nicotine on lung cancer progression}

Nicotine may induce a7nAChR expression in human SCLC cells via the Sp1/GATA regulation signaling pathway [31]. a7nAChR expression levels are elevated in SCC compared with adenocarcinoma of the lung, particularly in smokers [32, 54]. High a7nAChR expression levels in lung cancer cells may be involved in the nicotine-induced tumorigenesis $[32,54]$. a7nAChR levels in patients with SCC who are active smokers are correlated with their smoking history [31]. The function of a7nAChR-mediated lung cancer progression including in proliferation [31, 54-65], angiogenesis [66], and metastasis [39, 67-69], has been revealed (Fig. 2). The tumor-promoting effect is mediated by a7nAChR signaling pathways described in subsequent subsections.

\section{Cell proliferation}

$\alpha 7 \mathrm{nAChR}$ mediates the proliferative effects of nicotine in lung cancer cells [70]. Nicotine/ $47 \mathrm{nAChR}$ signaling enhances NSCLC cell proliferation by scaffolding protein $\beta$-arrestin-mediated activation of the Src and Rb-RAF protooncogene serine/ 


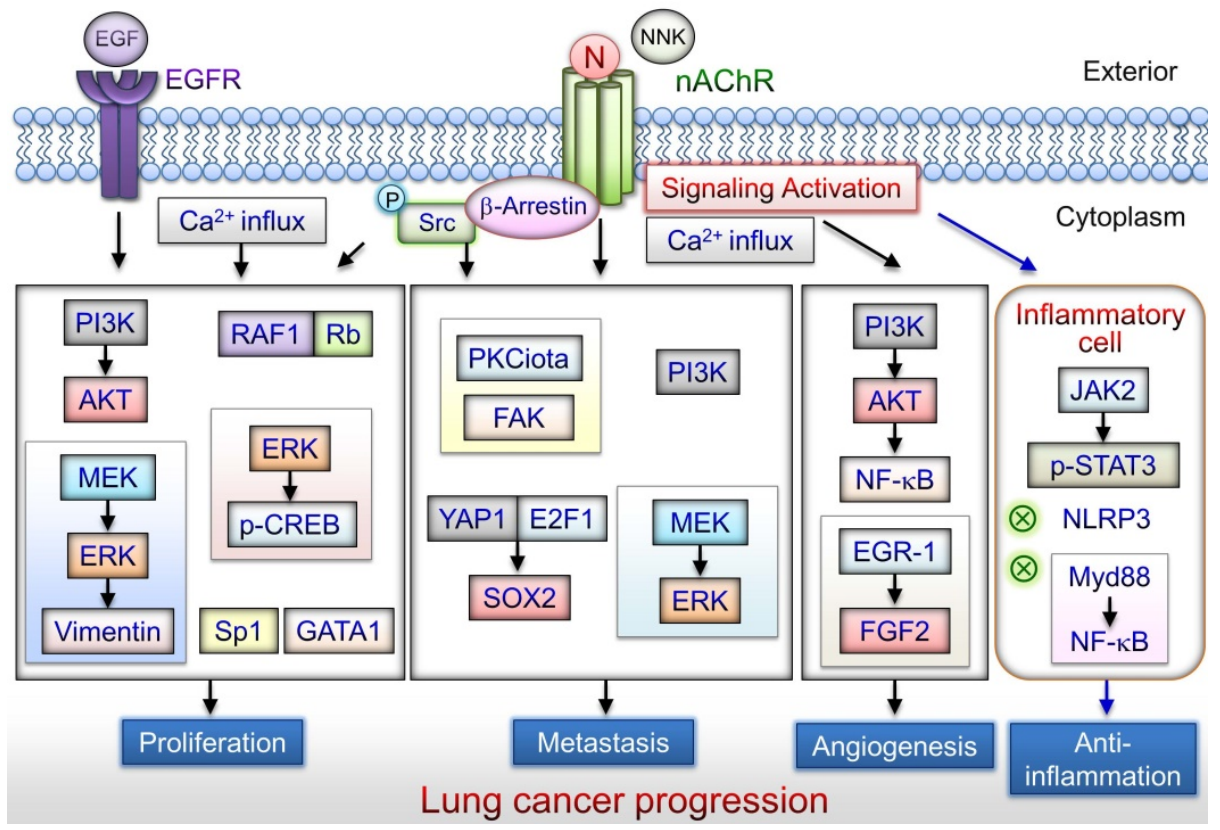

Figure 2: nAChR-mediated signaling pathways that lead to lung cancer progression. Nicotine/ $\alpha$ 7nAChR mediates the proliferative effects through several pathways including PI3K/AKT, MEK/ERK, RAF1/Rb, and Spl/GATA1 activation signaling in lung cancer cells. Cigarette smoking is associated with metastasis of lung cancer. Nicotine/a7nAChR can induce NSCLC cell migration and invasion via the MEK/ERK signaling pathway. NNK enhances lung cancer cell migration via activation of ERK or the Src-PKCiota-FAK signaling axis. Nicotine/a7nAChR can enhance the metastasis of lung cancer cells through activation of the YAPI-E2F1 signaling axis.

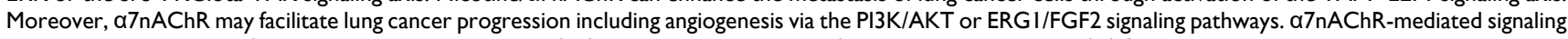
may be a potential target for attenuating the production of inflammatory cytokines in inflammatory cells. Nicotine/nAChR can promote lung cancer development via different signaling pathways. N: nicotine; NNK: 4-(methylnitrosamino)-1-(3-pyridyl)-1-butanone.

threonine-protein kinase (RAF-1) pathways [55]. Moreover, continuous exposure to nicotine in SCC of the lungs results in $\mathrm{a} 7 \mathrm{nAChRs}$ upregulation, which may enhance tumor growth [31]. Nicotine stimulates tumor growth and ERK activation in a murine orthotopic model of lung cancer [54]. A blockade of $\alpha 7 \mathrm{nAChRs}$ suppresses nicotine-induced lung cancer cell growth and vimentin expression through the MEK/ERK signaling pathway [63]. Consistent with these results, nicotine increased expression of $\mathrm{nAChR}$ and stimulated proliferation of SCC cell line [65]. a7nAChR may mediate the proliferative activity of nicotine in poorly differentiated NSCLC [56]. Nicotine-induced a7nAChR and a4nAChR expression in NSCLC cells, along with p-CREB and p-ERK1/2 activation accompanied by increased noradrenaline, leading to cell proliferation [57]. Nicotine/a7-nAChR promoted proliferation in human SCLC cells via the Sp1/GATA regulation signaling pathway [31]. NNK/a7nAChR may increase cell growth in SCLC cells via an influx of $\mathrm{Ca}^{2+}$ [60]. Nicotine stimulates NSCLC cell proliferation and $\mathrm{PPAR} \beta / \delta$ expression through activation of $\mathrm{PI} 3 \mathrm{~K} / \mathrm{mTOR}$ signals that suppress AP- $2 \alpha$ binding activity to $\operatorname{PPAR} \beta / \delta$ promoter [61]. $\alpha 7 n A C h R s$ or a9nAChRs mediated nicotine-induced cell proliferation and activation of the AKT and ERK signaling pathways [64]. The activated cell-membrane $\alpha 7 n A C h R s$ formed complexes with EGFR, whereas activated mitochondrial $\alpha 7 \mathrm{nAChRs}$ was physically associated with the intramitochondrial protein kinases PI3K and Src that increased expression of cyclin D1 and activation of ERK1/2 lead to lung cancer proliferation [71]. $\alpha$-Cobratoxin, a high-affinity $\alpha 7-n A C h R$ antagonist reduced tumor growth in nude mice orthotopically engrafted with NSCLC cells [59]. An $\alpha 7 \mathrm{nAChR}$ inhibitor (APS8) may suppress NSCLCs proliferative effects of nicotine [58]. These studies revealed that nicotine/ $\alpha 7 \mathrm{nAChR}$ signals mediate proliferation in lung cancer.

\section{Metastasis}

Cigarette smoke status and history are associated with lung cancer metastasis [72, 73]. a7nAChRs may mediate cancer cell growth depending on NSCLC differentiation status [56]. a7nAChR and heteromeric nAChRs can promote tumor invasion in NSCLC [56]. Nicotine/a7-nAChR can induce NSCLC cell migration and invasion via the MEK/ERK signaling pathway [39]. NNK promotes lung cancer cell migration and contactin- 1 expression via the a7nAChR-mediated ERK signaling pathway [67]. Moreover, NNK enhances lung cancer cell migration and invasion via activation of the c-SrcPKCiota-FAK signaling axis [68]. $\beta$-Cryptoxanthin may repress lung cancer cell motility through the downregulation of $\alpha 7 \mathrm{nAChR} / \mathrm{PI} 3 \mathrm{~K}$ signaling [69]. Nicotine/a7nAChR signaling enhance migration and 
the expression of SOX2 in NSCLC cell lines through the YAP-E2F1 signaling axis [23]. These studies suggest that $\mathrm{a} 7 \mathrm{nAChR}$ can enhance lung cancer cell metastasis through the activation of different signaling pathways.

\section{Angiogenesis}

$\alpha 7 \mathrm{nAChR}$ enhances angiogenesis via the PI3K/AKT pathway and NF- $\mathrm{KB}$ activation, which is partially dependent on vascular endothelial growth factor (VEGF) [74]. Nicotine/ $\alpha 7 n A C h R$ signaling mediates proangiogenic effects through angiogenesis and EMT [75]. MG624, an $\alpha 7 \mathrm{nAChR}$ antagonist, reduces nicotine-induced early growth response gene 1 (Egr-1) binding activity to the fibroblast growth factor 2 (FGF2) promoter that inhibits angiogenic effects in SCLC [66]. Thus, a7nAChR may facilitate lung cancer progression including angiogenesis; however, its detailed effect requires investigation.

\section{Anti-Inflammation}

a7nAChR attenuates ventilator-induced lung injury and plays an anti-inflammatory role in several inflammatory diseases [76-78]. Activation of inflammation-related receptors, such as toll-like receptors, enhances NF-kB signaling pathways in both acute and chronic inflammation that can considerably increase cancer risk [79]. Choline/ a7nAChR signaling modulates TNF release via the inhibition of NF-KB activation [80]. Moreover, nicotine/a7nAChR mediates anti-inflammatory action on macrophages via recruitment and activation of JAK2, initiating the STAT3 and SOCS3 signaling cascade [81]. Nicotine/a7nAChR suppresses TNF- $\alpha$ expression in human airway epithelial cells by inhibiting MyD88 and NF-KB activity [82]. An anti-inflammation study revealed that $\mathrm{a} 7 \mathrm{nAChR}$ signaling inhibits NLRP3 inflammasome activation by preventing mitochondrial DNA release [83]. Accumulating evidence suggests that the vagus nerve may modulate lung infection and inflammation through the $\alpha 7 \mathrm{nAChR}$ signaling pathway [84]. Thus, a7nAChR may be a potential target for attenuating inflammatory cytokine production in lung diseases [85].

Exposure to nicotine adversely affects dendritic cells, a cell type that has an important role in anticancer immunosurveillance [86]. Nicotine may suppress anticancer immunity by increasing or reducing number of regulatory $\mathrm{T}$ cells and $\mathrm{T}$ helper 17 cells, respectively [87]. Moreover, nicotine inhibits the cytotoxic activity of natural killer (NK) cells, and the effect of nicotine on NK cells can be abolished by $\beta 2 \mathrm{nAChR}$ deficiency [88]. However, to understand immune regulation and progression in lung cancer, the roles of nicotine-mediated pathways in distinct immune cells warrant investigation.

\section{The potential mechanisms of sirtuins on cancer progression}

Sirtuins play diverse roles in controlling the cell cycle and proliferation in response to stress, thus promoting cell survival, apoptosis, or senescence [89]. Sirtuin 1 (SIRT1) has been involved in decision making over cellular senescence or apoptosis in lung diseases including COPD and cancer [53, 90]. Cellular senescence is caused by replicative and stress-related senescence with p53 and p16 activation, respectively, leading to p21 activation and cell-cycle arrest. SIRT1 can function as p53 deacetylase that blocks p53-dependent pathways, thereby regulating cell-cycle and inactivating apoptotic process [91]. SIRT1 and p53 play vital roles in maintaining genomic stability and integrity, which favor cell survival and protect against tumorigenesis. Increased DNA damage and cellular senescence may contribute to accelerated lung aging and COPD pathogenesis [53]. SIRT6 can significantly suppress TGF- $\beta$-induced senescence of human bronchial epithelial cells via p21 degradation [92]. Moreover, SIRT6 may play a pivotal role in inhibiting fibrosis. SIRT1 and SIRT6 prevent telomere dysfunction during DNA replication [93]. SIRT1 and SIRT6 loss may promote aging and arise from oxidative stress through PI3K-mTOR signaling activation [94].

Sirtuins are responsible for cellular metabolic reprogramming and drug resistance by inactivating cell death pathways and promoting uncontrolled proliferation [90]. SIRT1 overexpression is associated with poor prognosis in patients with lung cancer [95]. SIRT1-mediated survival of cancer cells contributes to chemoresistance in tumors. Furthermore, SIRT1 is considerably expressed in the brain metastastic tissues of patients with NSCLC [96]. SIRT1 may promote breast cancer progression through modulating AKT activity [97]. SIRT1 was significantly overexpressed in human prostate cancer cells, and SIRT1 inhibition contributes to suppress cancer cell growth [98]. SIRT1 limits prostatic intraepithelial neoplasia in SIRT1-knockout mice. In $\mathrm{A} / \mathrm{J}$ mice, $\beta$-cryptoxanthin, strongly associated with reduced lung cancer risk, restores nicotine-reduced lung SIRT1 levels to that normal and inhibits nicotine-promoted lung tumorigenesis and emphysema [99]. In addition, SIRT1 levels decrease in some human cancers including glioma, bladder, and ovarian cancer [100]. SIRT1 also acts as a tumor suppressor via the c-Myc-SIRT1 feedback loop that regulates cell growth and transformation [101]. Thus, the tumor suppressor or promoter role of sirtuins in cancer progression may 


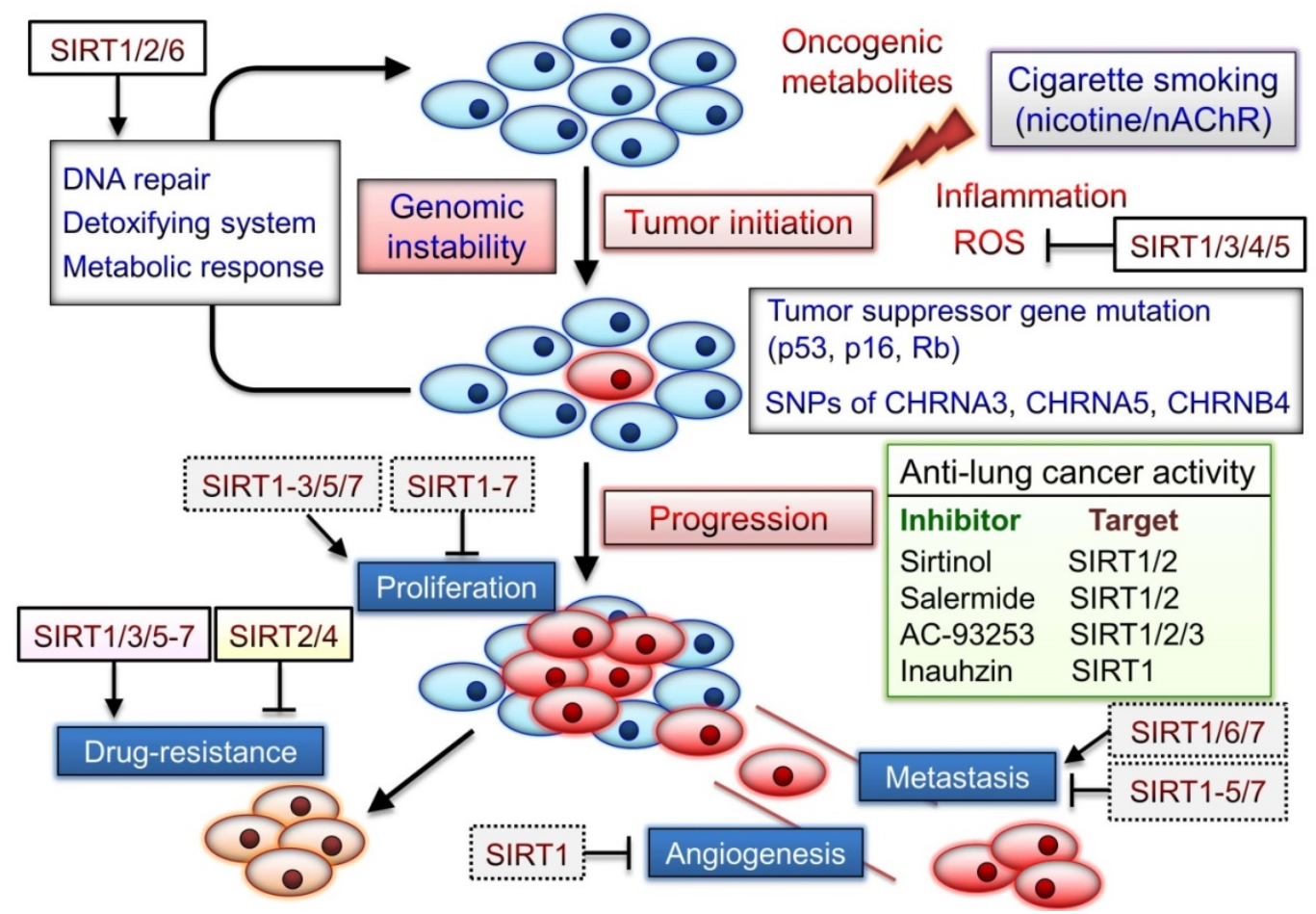

Figure 3: Roles of sirtuins may be involved in nicotine/nAChR-mediated signaling pathway. Cigarette smoke form carcinogens, including polycyclic aromatic hydrocarbons and the nicotine-derived nitrosamines 4-(methylnitrosamino)-1-(3-pyrydyl)-1-butanone (NNK) and N-nitrosonornicotine (NNN). Tumor suppressor mutations caused by these carcinogens may initiate carcinogenesis. NNK and NNN also significantly contribute to tumor development via activation of nAChRs signaling. SNPs located in a region of chromosome region 15q25 that contains nAChR subunits (CHRNA5, CHRNA3, and CHRNB4) are significantly associated with lung cancer risk. Sirtuins can exert their capacity to respond to environmental changes, and their expression is often altered in cancer. However, the tumor suppressor or promoter role of sirtuins in cancer progression may depend on their tissue- and cancer-specific expression and examined conditions. Several sirtuin inhibitors can suppress lung cancer development and blockade of sirtuins may be a potential anticancer strategy. The dotted box indicated the roles of sirtuins in other cancer types.

depend on their tissue- and cancer-specific expression and the examined conditions. Similarly, SIRT6 plays functions of both tumor promoter and suppressor in the development of different cancer, potentially depending on specific tissue [90].

The SIRT1 inhibitor sirtinol induces senescence-like growth arrest through impaired activation of RAS-mitogen-activated protein kinase (MAPK) signaling in human lung cancer cells [102]. The combination of inauhzin (SIRT1 inhibitor) and cisplatin or doxorubicin can considerably reduce NSCLC cell growth in a p53-dependent manner [103]. Two SIRT2 inhibitors AEM1 and AEM2 can induce p53-dependent proapoptotic activity in NSCLC cells [104]. Moreover, AEM2 demonstrates similar inhibition of SIRT2 as AC-93253. SIRT1/2 inhibitor, salermide, can increase death receptor 5 expression via the ATF4-ATF3-CHOP axis and contribute to NSCLC cell apoptosis [105]. Therefore, sirtuins play notable roles in both lung cancer development and the nicotine/nAChR-regulated signaling (Fig. 3). Although several sirtuins can function as both tumor promoters and suppressors, SIRT1/3/5-7 blockade may aid in effective chemotherapy, as described in the next section.

\section{The potential mechanisms of Nicotine and sirtuins on drug resistance}

Nicotine may reduce the cytotoxic effects of chemotherapy and radiotherapy that cause poor therapeutic response [87, 106]. Nicotine-mediated tumor-promoting effects are apparently mediated by nAChRs expressed on cell membranes and by mitochondria [87]. Additionally, mitochondria are critical mediators of cancer progression, as this process requires flexibility to adapt to cellular and environmental alterations in addition to cancer therapies [107]. Nicotine-impaired metabolism and mitochondrial defects were critical in metabolic responses to cancer progression [108]. Activation of cell-membrane and mitochondrial nAChRs produces a combination of growth-promoting and antiapoptotic signals that implemented the tumor-promoting action of nicotine in lung cells [71]. Furthermore, nAChRs were identified to control either CaKMII or Src-dependent signaling pathways in mitochondria that protect cells from apoptosis [109].

Nicotine also permeated cells and activated mitochondrion-nAChRs coupling to inhibit 
mitochondrial permeability transition pore (mPTP) opening, preventing apoptosis [62]. Nicotine-induced survival may occur by a mechanism of multisite phosphorylation of BAD, which may lead to human lung cancer and/or chemoresistance development [110]. Activation of nicotine- $a 7 \mathrm{nAChR}$ signaling can trigger membrane depolarization, which activates voltage-gated calcium channels and subsequently activates the MAPK pathway, possibly increasing B-cell lymphoma-2 (Bcl-2) expression and apoptosis downregulation [111]. Nicotine prevents cisplatinmediated apoptosis by regulating a $5 \mathrm{nAChR} / \mathrm{AKT}$ signaling and several mitochondria proteins including Bcl-2, Bax, survivin, and caspase 3 in gastric cancer cells [112]. Long-term nicotine exposureinduced chemoresistance is mediated by STAT3 activation and ERK1/2 downregulation via nAChR and $\beta-A R$ in bladder cancer cells [113]. Emerging evidence suggests that feedback activation of STAT3 signaling is a common cause of drug resistance to receptor tyrosine kinase-targeted therapies and conventional chemotherapy [114]. Long-term exposure to NNK combined with arecoline activated EGFR/AKT signaling is involved in antiapoptosis, cancer stem cell properties, and cisplatin resistance in head and neck SCC (HNSCC) cells [115]. Nicotine/a9nAChR-PPM1F signaling can attenuate p-p53 (Ser-20)- and p-BAX (Ser-184)-induced proapoptotic pathways [116]. Therefore, nAChRs may be a promising molecular target to arrest lung cancer progression and reopen mitochondrial apoptotic pathways. Nicotine can induce erlotinib resistance via the crosstalk between a1nAChR and EGFR/AKT/ ERK signaling pathways in NSCLC [117]. A recent study suggested that smoking containing nicotine causes resistance to erlotinib therapy in NSCLC [118].

Sirtuins can exert their capacity to respond to environmental changes and their expression is often altered in cancer [89]. SIRT1, SIRT3, SIRT4, and SIRT7 are strongly expressed in lung adenocarcinoma, whereas SIRT5 is highly expressed in SCC [119]. Analysis of the TCGA NSCLC dataset revealed that high expression levels of SIRT2/6 were associated with longer overall survival (OS) [119]. However, high SIRT6 expression was associated with poor OS in 98 patients with NSCLC [120]. Nicotine enhanced oxidative stress and activates NF-кB [121]. Several sirtuins are critical in inhibiting excessive, damaging levels of ROS that drive cancer drug resistance [122]. Nuclear SIRT1 promotes ROS stress resistance via the deacetylation of several transcriptional regulators, including p53, forkhead homeobox type O (FOXO) proteins, PGC-1a, heat shock factor protein 1 (HSF1), and nuclear erythroid factor 2-related factor 2 (NRF2), and this contributes to antioxidant production [123].
Studies have suggested that mitochondrial-sirtuins (SIRT3, SIRT4, and SIRT5) are members of a family of $\mathrm{NAD}^{+}$-dependent deacetylases and are implicated in the oxidative stress response through the regulation of mitochondrial metabolism and antioxidant mechanisms [124-126]. Mitochondrial SIRT3 may coordinate ROS; SIRT5 also limits ROS by activating SOD1 and NRF2 to maintain cellular redox homeostasis [122, 126, 127]. Thus, sirtuins may promote cancer cell survival by limiting ROS that would lead to cancer drug resistance. Several recent studies have supported the presence of sirtuins-mediated drug resistance with human cancers (Table 1). Some sirtuins regulate lung cancer progression, as described in the next subsection, and signaling molecules are associated with drug resistance.

\section{SIRT 1}

Nicotine can upregulate SIRT1 expression in a time- and concentration-dependent manner [128]. $\mathrm{BaP}$, a carcinogen in cigarette smoke, can induce SIRT1 in human bronchial epithelial cells [129]. SIRT1 is involved in BaP-induced transformation associated with TNF- $\alpha-\beta$-catenin axis activation and is a potential therapeutic target for lung cancer [129]. The SIRT1-PARP-1 axis plays a critical role in the regulation of cigarette smoke-induced autophagy and has notable implications for understanding the mechanisms of cigarette smoke-induced cell death and senescence [130]. a7nAChR-SIRT1 axis activation alleviates angiotensin II-induced VSMC senescence [131]. Recent studies have focused on the biological functions of SIRT1 in metabolic diseases, cancer, aging and cellular senescence, inflammatory signaling in response to environmental stress, and cell survival [132-135]. SIRT1 expression was a strong predictor for poor OS and progression-free survival in patients with NSCLC who underwent platinum-based chemotherapy [136]. Silencing of SIRT1 could significantly enhance the chemosensitivity of lung cancer cells to cisplatin treatment [136]. SIRT1 was negatively associated with proapoptotic factors BAD, BAX, and BID in TCGA NSCLC patients [119]. SIRT1 suppression sensitizes lung cancer cells to WEE1 inhibitor-induced DNA damage and apoptosis [137]. SIRT1 deacetylates and inactivates p53, allowing cells to bypass apoptosis [138]. The transcription factor FOXO 3 alpha (FOXO3a) may induce the expression of several antioxidant genes, including $\mathrm{Mn}$ superoxide dismutase (MnSOD), catalase, peroxiredoxins 3 and 5 (Prx3 and Prx5, respectively), thioredoxin 2 (Trx2), thioredoxin reductase 2 (TR2), and uncoupling protein 2 (UCP-2) [139]. SIRT1-mediated deacetylation of FOXO3a increases 
cell survival in response to oxidative stress [140]. Moreover, SIRT1 may play a role in the acquisition of and have potential as a therapeutic target for ovarian aggressiveness and chemoresistance in ovarian cancer cancer [141].

Table 1. Effects of sirtuins on cancer drug resistance

\begin{tabular}{|c|c|c|c|c|c|}
\hline $\begin{array}{l}\text { Types of } \\
\text { sirtuin }\end{array}$ & Types of cancer & Drug & Effect of cancer drug resistance & $\begin{array}{l}\text { Year of } \\
\text { publication }\end{array}$ & Ref \\
\hline SIRT1 & CRC & TRAIL & miR-128 suppressed SIRT1 expression to sensitize TRAIL-induced apoptosis & 2018 & [177] \\
\hline SIRT1 & Breast cancer & Paclitaxel & $\begin{array}{l}\text { A SIRT1-PRRX1-KLF4-ALDH1 circuitry regulates breast cancer stemness and } \\
\text { metastasis. KLF4 inhibitor Kenpaullone sensitizes breast cancer cells }\end{array}$ & 2018 & [178] \\
\hline SIRT1 & Cervical cancer & Paclitaxel & $\begin{array}{l}\text { Knockdown of SIRT1 promotes apoptosis of paclitaxel-resistant human cervical } \\
\text { cancer cells }\end{array}$ & 2018 & [179] \\
\hline SIRT1 & ATC & Doxorubicin & $\begin{array}{l}\text { 6-phosphogluconate dehydrogenase (6PGD) was critically involved in ATC } \\
\text { resistance to doxorubicin. Decreased enzymatic activity of SIRT1 in response to 6PGD } \\
\text { inhibition in doxorubicin-resistant ATC cells }\end{array}$ & 2018 & [180] \\
\hline SIRT1 & Cervical cancer & Doxorubicin & $\begin{array}{l}\beta 2-\mathrm{AR} \text { activation induces chemoresistance by modulating p53 acetylation through } \\
\text { upregulating Sirt1 in cervical cancer cells }\end{array}$ & 2017 & [181] \\
\hline SIRT1 & Gastric cancer & Cisplatin & $\begin{array}{l}\text { miR-132 regulated SIRT1/CREB/ABCG2 signaling pathway contributes to cisplatin } \\
\text { resistance }\end{array}$ & 2017 & [182] \\
\hline SIRT1 & $\mathrm{HCC}$ & Oxaliplatin & $\begin{array}{l}\text { LncRNA HULC triggered autophagy by stabilizing SIRT1 and attenuates } \\
\text { chemosensitivity of HCC cells }\end{array}$ & 2017 & [183] \\
\hline $\begin{array}{l}\text { SIRT1/ } \\
\text { SIRT3 }\end{array}$ & $\begin{array}{l}\text { Breast and } \\
\text { Cervical cancer }\end{array}$ & Etoposide & $\begin{array}{l}\text { Cancer cells with low SIRT1 levels maintained their resistance and survival by } \\
\text { increasing SIRT3 expression }\end{array}$ & 2017 & [148] \\
\hline SIRT1 & Prostate cancer & Docetaxel & $\begin{array}{l}\text { The UCA1-miR-204-SIRT1 axis modulates docetaxel sensitivity of prostate cancer } \\
\text { cells }\end{array}$ & 2016 & [184] \\
\hline SIRT1 & Breast cancer & Tamoxifen & Brachyury mediates tamoxifen resistance by regulating SIRT1 & 2016 & [185] \\
\hline SIRT1 & Bladder cancer & Capsaicin & $\begin{array}{l}\text { Capsaicin inhibited multiple bladder cancer cells by inhibiting tumor-associated } \\
\text { NADH oxidase (tNOX) and SIRT1 }\end{array}$ & 2016 & [186] \\
\hline SIRT1 & ATL & Etoposide & $\begin{array}{l}\text { SIRT1 inhibition enhances chemosensitivity and survival of ATL cells by reducing } \\
\text { DNA double-strand repair }\end{array}$ & 2015 & [187] \\
\hline SIRT1 & $\begin{array}{l}\text { Endometrial } \\
\text { carcinoma }\end{array}$ & Cisplatin and paclitaxel & $\begin{array}{l}\text { SIRT1 overexpression significantly enhanced drug resistance. Selective SIRT1 } \\
\text { inhibitor (EX527) significantly increased chemosensitivity }\end{array}$ & 2015 & [188] \\
\hline SIRT1 & CML & $\begin{array}{l}\text { Hsp90 inhibitors (17-AAG } \\
\text { and AUY922) }\end{array}$ & $\begin{array}{l}\text { SIRT1 inhibitors (amurensin G and EX527) effectively potentiated sensitivity of } \\
\text { Hsp90 inhibitors }\end{array}$ & 2015 & [189] \\
\hline SIRT1 & ESCC & Cisplatin & $\begin{array}{l}\text { Overexpression of SIRT1 may cause resistance of ESCC cells to cisplatin through } \\
\text { Noxa expression }\end{array}$ & 2015 & [190] \\
\hline SIRT1 & PC & $\begin{array}{l}\text { 5-fluorouracil (5-FU) and } \\
\text { gemcitabine }\end{array}$ & $\begin{array}{l}\text { Overexpression of miR- } 494 \text { inhibited chemoresistance of PC by downregulating } \\
\text { SIRT1 and c-Myc }\end{array}$ & 2015 & [191] \\
\hline SIRT1 & CRC & $5-\mathrm{FU}$ & $\begin{array}{l}\text { SIRT1/PGC1a-dependent increase in oxidative phosphorylation leads to CRC drug } \\
\text { resistance }\end{array}$ & 2015 & [192] \\
\hline SIRT1 & CML & Imatinib & Divalproex sodium enhances antileukemic effects of imatinib in CML through SIRT1 & 2015 & [193] \\
\hline SIRT1 & AML & TKI (Quizartinib, AC220) & $\begin{array}{l}\text { Inhibition of SIRT1 by SIRT1 inhibitor Tenovin-6 (TV6) enhanced TKI-mediated } \\
\text { sensitivity }\end{array}$ & 2014 & [194] \\
\hline SIRT1 & Thyroid cancer & Etoposide & SIRT1-Foxp3 signaling confers drug resistance & 2014 & [195] \\
\hline SIRT1 & Breast cancer & TRAIL & $\begin{array}{l}\text { Metformin mediates miR-34a to suppress the SIRT1/PGC-1a/NRF2 pathway and } \\
\text { increases drug sensitivity }\end{array}$ & 2014 & [196] \\
\hline SIRT1 & CML & $\begin{array}{l}\text { TKIs (imatinib, nilotinib or } \\
\text { dasatinib) }\end{array}$ & $\begin{array}{l}\text { All-trans-retinoic acid (ATRA) effectively blocked acquisition of BCR-ABL mutations } \\
\text { and resistance. ATRA inhibited NAD+-dependent SIRT1 deacetylase via CD38 } \\
\text { expression }\end{array}$ & 2014 & [197] \\
\hline SIRT2 & RCC & $5-\mathrm{FU}$ & SIRT2+ cells mediates RCC drug resistance & 2018 & [198] \\
\hline SIRT2 & AML & $\begin{array}{l}\text { Daunorubicin, } \\
\text { arabinocytidine }\end{array}$ & SIRT2 mediates multidrug resistance in AML cells via ERK1/2 signaling pathway & 2016 & [199] \\
\hline SIRT2 & Melanoma & Doxorubicin & AC-93253, a SIRT2 inhibitor increases drug sensitivity & 2015 & [200] \\
\hline SIRT3 & Synovial sarcoma & Pazopanib & Knockdown of SIRT3 confers increased resistance to chemotherapeutic agents & 2018 & [201] \\
\hline SIRT3 & $\mathrm{HCC}$ & Sorafenib & SIRT3 protein expression was significantly higher in patients treated with metformin & 2017 & [202] \\
\hline SIRT3 & Glioma & Linalool & $\begin{array}{l}\text { Overexpression of SIRT3 significantly inhibited a linalool-induced increase of } \\
\text { mitochondrial ROS production and apoptotic cell death }\end{array}$ & 2017 & [203] \\
\hline SIRT3 & Breast cancer & Cisplatin & $\begin{array}{l}\text { SIRT3 silencing sensitizes breast cancer cells to cytotoxic treatments through ROS } \\
\text { production }\end{array}$ & 2017 & [124] \\
\hline SIRT4 & CRC & $5-\mathrm{FU}$ & SIRT4 increased the sensitivity of CRC cells to 5-FU & 2016 & [204] \\
\hline SIRT5 & NSCLC & CDDP, 5-FU or bleomycin & SIRT5 facilitates cancer cell growth and drug resistance in NSCLC cells & 2014 & [127] \\
\hline SIRT6 & $\mathrm{HCC}$ & Doxorubicin & SIRT6 increased doxorubicin resistance via FOXO3 activity & 2018 & [205] \\
\hline SIRT6 & NSCLC & Gefitinib & $\begin{array}{l}\text { Astragaloside IV sensitizes NSCLC cells to gefitinib potentially via regulation of } \\
\text { SIRT6 }\end{array}$ & 2017 & [206] \\
\hline SIRT6 & $\mathrm{PC}$ & Gemcitabine & Quinazolinedione SIRT6 inhibitors sensitize cancer treatment & 2015 & [207] \\
\hline SIRT6 & NSCLC & Paclitaxel & SIRT6 knockdown NSCLC cells improved drug sensitivity & 2015 & [120] \\
\hline SIRT6 & Breast cancer & Trastuzumab (Herceptin) & $\begin{array}{l}\text { MDM2-mediated degradation of SIRT6 phosphorylated by AKT1 promotes drug } \\
\text { resistance }\end{array}$ & 2014 & [208] \\
\hline SIRT7 & NSCLC & Gemcitabine & Depletion of SIRT7 promoted drug sensitivity & 2018 & [151] \\
\hline SIRT7 & $\begin{array}{l}\text { Breast cancer, } \\
\text { osteosarcoma, and } \\
\text { ovarian cancer }\end{array}$ & Cisplatin, Doxorubicin & $\begin{array}{l}\text { SIRT7 inhibition significantly increases stress resistance and modulates insulin/IGF-1 } \\
\text { signaling pathways }\end{array}$ & 2014 & [209] \\
\hline
\end{tabular}

CRC, Colorectal cancer; ATC, Anaplastic thyroid carcinoma; HCC, Hepatocellular carcinoma; ATL, Adult T-cell leukemia-lymphoma; CML, Chronic myeloid leukemia; ESCC, Esophageal squamous cell carcinoma; PC, Pancreatic cancer; AML, Acute myeloid leukemia; RCC, Renal cell carcinoma; and NSCLC, Non-small-cell lung carcinoma. 


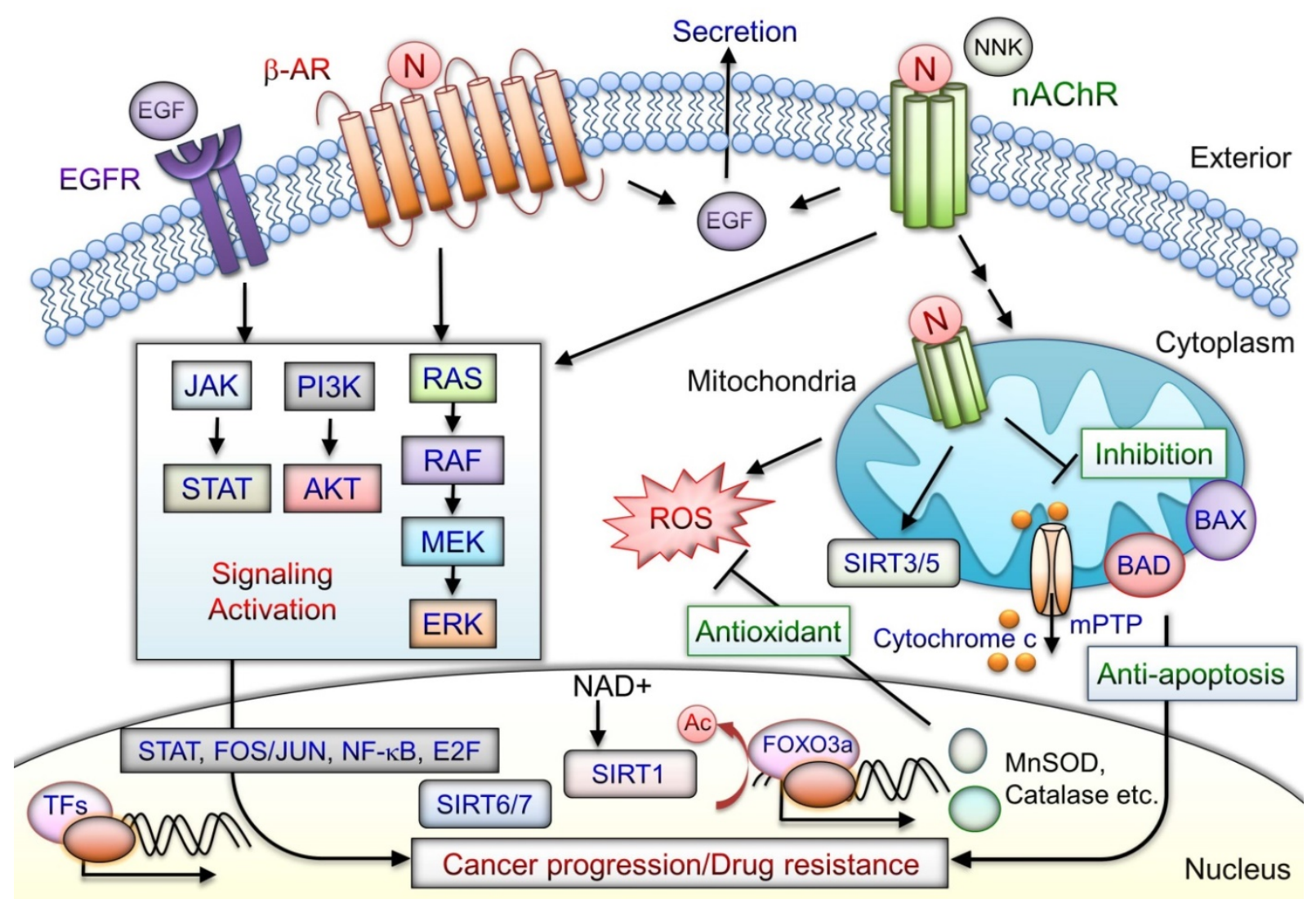

Figure 4: Schematic of mediation of tumor-promoting actions by nicotine/nAChR. Nicotine interacts with nAChR and stimulates activation and crosstalk with $\beta$-AR and EGFR downstream, signaling to promote cancer progression. Activation of $n A C h R s$ and $\beta$-AR mediates EGF secretion to further transactivate EGFRs. In cancer cells, the signaling pathways downstream of nAChRs promote drug resistance and antiapoptosis by activating the transcription factors including STAT, NF-KB, Jun/Fos, and E2F through JAK, PI3K/AKT, RAS, RAF, and the MAPK signaling cascade. Mitochondrial nAChRs trigger phosphatidyl-inositol-3-kinase (PI3K) and AKT signaling pathways that prevent mPTP opening and cytochrome $c$ release. Nicotine-induced antiapoptosis and drug resistance may include several mechanisms involved in overexpression of sirtuin proteins, phosphorylation of BAD, and blockade of BAX translocation, leading to tumor cell development. SIRT3 and SIRT5 are mitochondrial proteins. SIRT6 and SIRT7 are localized in the nucleus. SIRT1-mediated deacetylation of FOXO3a can induce expression of antioxidant enzymes including MnSOD and catalase that increase cell survival during cellular oxidative stress. Consequently, nicotine/nAChR mediates antiapoptotic pathways and concurrently crosstalks with $\beta-A R$ or EGFR signaling activation may lead to cancer progression. N: nicotine; Ac: acetylation; NNK: 4-(methylnitrosamino)-1-(3-pyridyl)-1-butanone.

\section{SIRT2-SIRT7}

SIRT3, located in mitochondria, is correlated with NSCLC malignancy [142]. a7nAChRs activation inhibits platelet-derived growth factor-induced cells migration by activating the mitochondrial deacetylase SIRT3, implying a critical role for a7nAChRs in mitochondrial biology and PDGF-related diseases [143]. The activity of SIRT3 can protect cancer cells from chemotherapy-induced oxidative stress [144, 145]. Additionally, SIRT3 promotes the activation of AKT signaling pathways in NSCLC [142]. SIRT3 promoted p53 degradation in PTEN-deficient NSCLC cell lines via the ubiquitin-proteasome pathway [146]. SIRT3 can also mediated FOXO3a nuclear translocation that activates MnSOD and catalase expression [147]. Notably, SIRT1 knockdown cells can increase SIRT3 expression and cell survival and have relatively high resistance to $\mathrm{H}_{2} \mathrm{O}_{2}$ or etoposide treatment [148]. SIRT3 might be a therapeutic target for breast cancer, improving the effectiveness of cisplatin and tamoxifen treatments [124]. SIRT5 prevents cigarette smoke extract-induced apoptosis in lung epithelial cells via FOXO3 deacetylation [127]. Besides, SIRT5 knockdown makes lung cancer cells more sensitive to drug (cisplatin, 5-fluorouracil or bleomycin) treatment [127]. SIRT5 depletion suppresses the expression of NRF2 and its downstream drug-resistance genes [127].

Patients with high cytosol expression but low nuclear expression of SIRT6 can have poor clinical outcomes of lung cancer [120]. Furthermore, SIRT6 knockdown in NSCLC cell lines can improve paclitaxel sensitivity by reducing NF- $\mathrm{KB}$ and Beclin1 (autophagy mediator) levels [120]. Cigarette smoke increases SIRT6 expression in vivo (mice) and in vitro (rheumatoid arthritis synovial fibroblasts) [149]. Reduced SIRT6 expression mediates the augmentation of radiation-induced apoptosis via cAMP signaling in lung cancer cells [150]. A recent report revealed that SIRT7 depletion promotes 
gemcitabine-induced cell death [151]. Functioning as an oncogene, SIRT7 can be suppressed by miR-3666, which could increase NSCLC cell apoptosis [152].

Thus, the aforementioned studies together have demonstrated tumor progression modulated by the SIRT1, SIRT3, and SIRT5-7, along with the tumor-suppressive effects of SIRT2 and SIRT4. SIRT2 mediates the ROS production and p27 levels, leading to lung cancer cell apoptosis and cell-cycle arrest [153]. SIRT2 overexpression increases NSCLC cells' sensitivity to cisplatin treatment [153]. Moreover, recent findings suggest that SIRT4 inhibits lung cancer progression through mitochondrial dynamics mediated by the ERK-Drp1 pathway [154]. At present, one clinical trial (NCT02416739) is studying the combinatorial effects of the human sirtuin inhibitor (nicotinamide) and EGFR-TKI in NSCLC. The discovery of specific SIRT regulation and EGFR-TKI treatment would help elucidate the roles of sirtuins in lung cancer development. Although sirtuin clearly is critical in carcinogenesis, the crucial mechanisms by which the nicotine-mediated signaling or specific sirtuin pathways in different cell context lead to drug resistance require elucidation.

Cell-membrane nAChRs implement upregulation of proliferative and survival genes [62]. Nicotine can promote oral precancerous growth through suppression of apoptosis by upregulating a7nAChR and peroxiredoxin [155]. a7nAChRmediated cell protection, through JAK2/PI3K/AKT/ signal transducer and activator of transcription 3(STAT3)/NF-kB activation, leads to Bcl-2 production [156]. Nicotine binds to $\mathrm{nAChRs}$ and stimulates secretion several factors including epidermal growth factor (EGF), VEGF, and neurotransmitters [157]. Nicotine/nAChRs mediates EGF secretion and subsequent EGFR signaling activation, thus contributing to antiapoptosis [18]. Nicotine and NNK also bind to $\beta$-ARs and promote survival signaling cascades [18, 30]. Moreover, tissue-specific expression of $\alpha 7 \beta 2, \alpha 3 \beta 2$, $\alpha 3 \beta 4$, and $\alpha 4 \beta 2$ nAChRs located in the mitochondria outer membrane with anion channels that regulate the release of proapoptotic cytochrome $\mathrm{c}$ or ROS production has been observed [78, 158, 159]. $\mathrm{nAChR}$ signaling in mitochondria is stimulated and engages PI3K/AKT kinases, similar to those activated by plasma membrane nAChRs. Nicotine contributes to progression and erlotinib resistance in an NSCLC xenograft model through the nAChR-EGFR cooperation [117]. The nicotine-mediated a5nAChR/ AKT signaling pathway prevents cisplatin-induced cancer cell apoptosis [112]. Blockade of a7nAChRs inhibited nicotine-induced tumor growth and vimentin expression in NSCLC through the RAS-RAF-MAPK kinase (MEK)-extracellular signal- regulated kinase (ERK) signaling pathway [63]. The nicotine and derivatives may mediate oncogenic signaling via nAChR, $\beta-A R$, and EGFR and combined with the effects of antiapoptosis in mitochondria that contribute to cancer progression (Fig. 4). The nicotine/nAChR signaling crosstalk with SIRT1/ 3/5-7 may contribute to cancer drug resistance.

\section{Conclusions and Future Directions}

Genome-wide association studies have indicated a strong link between nicotine/nAChRs and lung cancer risk [34, 38]. Nicotine might lead to suppressed apoptosis and cisplatin resistance via $\alpha 5 \mathrm{nAChR} / \mathrm{AKT}$ signaling [112]. In addition, $\alpha 7 \mathrm{nAChR}$ may be implicated in the $\mathrm{NAD}^{+} /$SIRT1 pathway, which promotes chemotherapeutic drug resistance [131]. Nicotine/a9nAChR signaling can reduce apoptotic pathways [116]. Nicotine-mediated cancer progression is mediated by nicotine/nAChRs signaling. By contrast to the tumor-suppressing role of SIRT2/4, the roles of SIRT1/6/7 and mitochondrial SIRT3/5 are strongly associated with drug resistance in lung cancer $[119,120,124,135,142,144,146$, 150-154]. However, SIRT1/2 inhibitor, sirtinol, can increase anticancer potential and chemosensitivity in several cancer cells [102, 160, 161]. SIRT1 may have contradictory roles in promoting or suppressing in different cell contexts or types of tumor development [162]. Moreover, shikonin causes apoptosis in some lung cancer cell lines via the FOXO3a/EGR1/SIRT1 signaling pathway activation [163]. In contrast to the tumor-suppressing role of SIRT1, the role of shikonin involves promoting liver cancer cell death by downregulating the SIRT1-MDR1/P-gp signaling pathway [164]. However, emerging evidence suggests that SIRT1 can promote cancer drug resistance (Table 1). Thus, an investigation to unravel cancer cellular contexts in which ROS are beneficial or harmful, with sirtuins having tumor-suppressing or promoting functions, would contribute to the literature. Thus, a series of more comprehensive studies are necessary to validate the underlying molecular mechanisms of the nicotine-mediated pathway with specific sirtuin and related targets in different types of cancer.

Nicotine activates $\alpha 7 \mathrm{nAChR}$ and $\beta 2 \mathrm{nAChR}$, and these two factors are associated with EGF and VEGEF receptors, respectively. However, activated mitochondrial $\alpha 7 \mathrm{nAChRs}$ and $\beta 4 \mathrm{nAChR}$ interacted with the PI3K and Src [62]. This interaction leads to increased cell proliferation and ROS-mediated apoptosis resistance through ERK signaling and mPTP inhibition, respectively [62]. The same group of researchers demonstrated a nicotine-mediated growth-promoting effect via interaction of $a 7 n A C h R$ with that EGF, a3nAChR with VEGF, a4nAChR with 
insulin-like growth factor I (IGF-I) and VEGF, whereas a9nAChR was with EGF, IGF-I, and VEGF. Similar to the binding affinity of cell-membrane nAChRs, nicotine can bind to mitochondrial nAChRs. Mitochondrial nAChRs coupled with the inhibition of mPTP opening causes tumor progression [71]. These results indicate that nicotine-mediated activation of the cell-membrane or mitochondrial nAChRs leads to tumor-promoting and antiapoptotic signals in tumor development. Therefore, nAChRs may be a potential molecular target to suppress lung cancer progression and trigger mitochondrial apoptotic pathways.

An accumulating body of evidence is demonstrating that long noncoding RNAs (lncRNAs) have various biological functions, including modulation of growth, cell differentiation, drug resistance, and cancer progression [165-167]. MALAT-1 is highly expressed and mediates poor progression in lung cancer [168]. LncRNA-SCAL1 (smoke and cancer-associated lncRNA1) can alleviate CS-mediated oxidative stress in airway epithelial cells [169]. Although lncRNAs were to be dysregulated in various human diseases, how IncRNAs connect with environmental exposures remains largely unknown. GAS5 may be proapoptotic and increase sensitivity to cell death due to environmental stressors [170, 171]. HOTAIR mediates EMT because of cigarette smoke extracts [172], and similar studies have indicated that MALAT1 is involved in cigarette smoke extractinduced EMT and malignant transformation [172]. Circulating extracellular vesicles (EVs) can transfer biomolecules, including ligands, cytokines, and genetic information, to recipient cells to enact functional changes [173]. EVs can contain relatively stable RNA species, including small noncoding RNAs and lncRNAs [174]. LncARSR is highly expressed in sunitinib-resistant renal cancer cells, and these drug-resistant cancer cells can transfer lncARSR to drug-sensitive recipient cells and acquire chemoresistance via exosomes [175]. Exosomes mediated transfer of lncRNA UCA1 can considerably increase tamoxifen resistance in estrogen receptor (ER)-positive breast cancer cells [176]. Thus, lncRNAs may cause cancer-acquired chemoresistance via exosomal pathway. However, whether nicotine promotes cancer drug resistance via the tumor environment communication remains unclear. Thus far, nicotine-mediated drug resistance induced by lncRNAs in lung cancer remains unclear. Therefore, nicotine-mediated drug resistance through lncRNA regulation in NSCLC warrants further exploration.

Over the past few years, nAChRs have been found to be selectively overexpressed in various cancers, including lung cancer. Targeting nAChRs signaling pathways can significantly attenuate nicotine-associated drug resistance. Several a7nAChR antagonists are potential anticancer drugs [38]. Collectively, studies have suggested that nAChR-induced antiapoptotic effects may play notable roles in drug resistance in lung cancer. Elucidation of the consequences of nicotine/nAChRs signaling crosstalk with other pathways and specific sirtuins may be crucial to therapeutic implications. These studies may facilitate the design of useful therapeutic strategies to reverse chemoresistance in patients with different types of cancer.

\section{Implication}

Nicotine and derived metabolites are associated with lung cancer risk in smokers. The $\mathrm{a} 7 \mathrm{nAChR}$ is significantly upregulated in NSCLC and correlates with its unfavorable prognosis. Activation of nicotine/a7nAChR signaling leads to lung cancer progression. Studies have suggested that nicotine/nAChR axis and SIRT1/3/5-7 mediates cancer drug resistance. Blockade of the signaling mediated by nicotine/nAChR and specific sirtuins may enhance the efficacy of chemotherapy.

\section{Abbreviations}

SCLC: small-cell lung carcinoma; NSCLC: non-small-cell lung carcinoma; EGFR: epithelial growth factor receptor; EGFR-TKI: EGFR-tyrosine

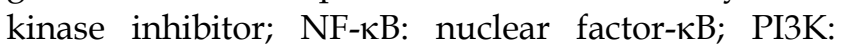
phosphoinositide 3-kinase; $\mathrm{BaP}$ : benzo[a]pyrene; PAH: polycyclic aromatic hydrocarbons; nAChRs: nicotinic acetylcholine receptors; $\beta$-AR: $\beta$-adrenergic receptors; NNK: 4-(methylnitrosamino)-1-(3-pyridyl)1-butanone; NNN: N-nitrosonornicotine; NNAL: 4-(methylnitrosamino)-1-(3-pyridyl)-1-butanol; SNP: single nucleotide polymorphism; RAF-1: protooncogene serine/threonine-protein kinase; MEK: mitogen-activated protein kinase kinase; ERK: extracellular signal-regulated kinases; MAPK: mitogen-activated protein kinase; EMT: epithelial-tomesenchymal transition; SOX2: sex-determining region Y-box 2; VEGF: vascular endothelial growth factor; Egr-1: growth response gene 1; FGF2: fibroblast growth factor 2; STAT3: signal transducer and activator of transcription 3; NLRP3: nucleotidebinding domain and leucine-rich repeat containing protein 3; ASC: adult stem cell; ROS: reactive oxygen species; NAC: N-acetyl-cysteine; mPTP: mitochondrial permeability transition pore; $\mathrm{Bcl} 2$ : B-cell lymphoma-2; HNSCC: head and neck squamous cell carcinoma; SIRT1: Sirtuin 1; TAM: tumor-associated macrophage; FOXO3: Forkhead box 3; NRF2: nuclear factor (erythroid-derived 2)-like 2; OS: overall survival; RFS: recurrence-free survival; and NRF2: nuclear factor erythroid-2-related factor. 


\section{Acknowledgments}

This work was supported by grants from the Ministry of Science and Technology of the Republic of China (MOST 107-2314-B-038-114 and 108-2314-B-038063-MY3), Ministry of Education of the Republic of China (DP2-107-21121-T04), Taipei Medical University (TMU107-AE1-B04), Taipei Medical University and Shuang Ho Hospital (106TMU-SHH18 and 107TMU-SHH-09).

\section{Authors' Contributions}

WLC, KYC, KYL, PHF and SMW contributed to writing the manuscript and revising it critically for important intellectual content. All authors read and approved the manuscript.

\section{Ethics Approval and Consent to Participate}

Not applicable.

\section{Competing Interests}

The authors have declared that no competing interest exists.

\section{References}

1. Siegel RL, Miller KD, Jemal A. Cancer statistics, 2018. CA Cancer J Clin. 2018; 68: 7-30.

2. Cheng TY, Cramb SM, Baade PD, Youlden DR, Nwogu C, Reid ME. The International Epidemiology of Lung Cancer: Latest Trends, Disparities, and Tumor Characteristics. J Thorac Oncol. 2016; 11: 1653-71.

3. Zappa C, Mousa SA. Non-small cell lung cancer: current treatment and future advances. Transl Lung Cancer Res. 2016; 5: 288-300.

4. Furrukh M. Tobacco Smoking and Lung Cancer: Perception-changing facts. Sultan Qaboos Univ Med J. 2013; 13: 345-58.

5. Sosa Iglesias V, Giuranno L, Dubois LJ, Theys J, Vooijs M. Drug Resistance in Non-Small Cell Lung Cancer: A Potential for NOTCH Targeting? Front Oncol. 2018; 8: 267.

6. Bethune G, Bethune D, Ridgway N, Xu Z. Epidermal growth factor receptor (EGFR) in lung cancer: an overview and update. J Thorac Dis. 2010; 2: 48-51.

7. Condoluci A, Mazzara C, Zoccoli A, Pezzuto A, Tonini G. Impact of smoking on lung cancer treatment effectiveness: a review. Future Oncol. 2016; 12: 2149-61.

8. Garces YI, Yang P, Parkinson J, Zhao X, Wampfler JA, Ebbert JO, et al. The relationship between cigarette smoking and quality of life after lung cancer diagnosis. Chest. 2004; 126: 1733-41.

9. Nishioka T, Luo LY, Shen L, He H, Mariyannis A, Dai W, et al. Nicotine increases the resistance of lung cancer cells to cisplatin through enhancing Bcl-2 stability. Br J Cancer. 2014; 110: 1785-92.

10. Liu $\mathrm{Q}, \mathrm{Yu} \mathrm{S}$, Zhao $\mathrm{W}$, Qin $\mathrm{S}$, Chu $\mathrm{Q}$, Wu K. EGFR-TKIs resistance via EGFR-independent signaling pathways. Mol Cancer. 2018; 17: 53.

11. Rojewski AM, Tanner NT, Dai L, Ravenel JG, Gebregziabher M, Silvestri GA, et al. Tobacco Dependence Predicts Higher Lung Cancer and Mortality Rates and Lower Rates of Smoking Cessation in the National Lung Screening Trial. Chest. 2018; 154: 110-8.

12. Schaal C, Chellappan S. Nicotine-Mediated Regulation of Nicotinic Acetylcholine Receptors in Non-Small Cell Lung Adenocarcinoma by E2F1 and STAT1 Transcription Factors. PLoS One. 2016; 11: e0156451.

13. Hecht SS. Tobacco carcinogens, their biomarkers and tobacco-induced cancer. Nat Rev Cancer. 2003; 3: 733-44.

14. Hecht SS. Tobacco smoke carcinogens and lung cancer. J Natl Cancer Inst. 1999; 91: 1194-210.

15. Phillips DH. Smoking-related DNA and protein adducts in human tissues. Carcinogenesis. 2002; 23: 1979-2004.

16. Schuller HM. Beta-adrenergic signaling, a novel target for cancer therapy? Oncotarget. 2010; 1: 466-9.

17. Carlisle DL, Liu X, Hopkins TM, Swick MC, Dhir R, Siegfried JM. Nicotine activates cell-signaling pathways through muscle-type and neuronal nicotinic acetylcholine receptors in non-small cell lung cancer cells. Pulm Pharmacol Ther. 2007; 20: 629-41.

18. Singh S, Pillai S, Chellappan S. Nicotinic acetylcholine receptor signaling in tumor growth and metastasis. J Oncol. 2011; 2011: 456743.

19. Schuller HM. Is cancer triggered by altered signalling of nicotinic acetylcholine receptors? Nat Rev Cancer. 2009; 9: 195-205.

20. Church TR, Anderson KE, Caporaso NE, Geisser MS, Le CT, Zhang Y, et al. A prospectively measured serum biomarker for a tobacco-specific carcinogen and lung cancer in smokers. Cancer Epidemiol Biomarkers Prev. 2009; 18: 260-6.

21. Schaal C, Chellappan SP. Nicotine-mediated cell proliferation and tumor progression in smoking-related cancers. Mol Cancer Res. 2014; 12: 14-23.

22. Davis R, Rizwani W, Banerjee S, Kovacs M, Haura E, Coppola D, et al. Nicotine promotes tumor growth and metastasis in mouse models of lung cancer. PLoS One. 2009; 4: e7524.

23. Schaal CM, Bora-Singhal N, Kumar DM, Chellappan SP. Regulation of Sox 2 and stemness by nicotine and electronic-cigarettes in non-small cell lung cancer. Mol Cancer. 2018; 17: 149.

24. Mai H, May WS, Gao F, Jin Z, Deng X. A functional role for nicotine in Bcl2 phosphorylation and suppression of apoptosis. J Biol Chem. 2003; 278: 1886-91.

25. Maneckjee R, Minna JD. Opioid and nicotine receptors affect growth regulation of human lung cancer cell lines. Proc Natl Acad Sci U S A. 1990; 87: 3294-8.

26. West KA, Brognard J, Clark AS, Linnoila IR, Yang X, Swain SM, et al. Rapid Akt activation by nicotine and a tobacco carcinogen modulates the phenotype of normal human airway epithelial cells. J Clin Invest. 2003; 111: 81-90.

27. Hecht SS. Lung carcinogenesis by tobacco smoke. Int J Cancer. 2012; 131: 2724-32.

28. Baker RR, Dixon M. The retention of tobacco smoke constituents in the human respiratory tract. Inhal Toxicol. 2006; 18: 255-94.

29. Schuller HM, Orloff M. Tobacco-specific carcinogenic nitrosamines. Ligands for nicotinic acetylcholine receptors in human lung cancer cells. Biochem Pharmacol. 1998; 55: 1377-84.

30. Lam DC, Girard L, Ramirez R, Chau WS, Suen WS, Sheridan S, et al. Expression of nicotinic acetylcholine receptor subunit genes in non-small-cell lung cancer reveals differences between smokers and nonsmokers. Cancer Res. 2007; 67: 4638-47.

31. Brown KC, Perry HE, Lau JK, Jones DV, Pulliam JF, Thornhill BA, et al. Nicotine induces the up-regulation of the alpha7-nicotinic receptor (alpha7-nAChR) in human squamous cell lung cancer cells via the Sp1/GATA protein pathway. J Biol Chem. 2013; 288: 33049-59.

32. Bordas A, Cedillo JL, Arnalich F, Esteban-Rodriguez I, Guerra-Pastrian L, de Castro J, et al. Expression patterns for nicotinic acetylcholine receptor subunit genes in smoking-related lung cancers. Oncotarget. 2017; 8: 67878-90

33. Parsons A, Daley A, Begh R, Aveyard P. Influence of smoking cessation after diagnosis of early stage lung cancer on prognosis: systematic review of observational studies with meta-analysis. BMJ. 2010; 340: b5569.

34. Macqueen DA, Heckman BW, Blank MD, Janse Van Rensburg K, Park JY, Drobes DJ, et al. Variation in the alpha 5 nicotinic acetylcholine receptor subunit gene predicts cigarette smoking intensity as a function of nicotine content. Pharmacogenomics J. 2014; 14: 70-6.

35. Chen LS, Baker T, Hung RJ, Horton A, Culverhouse R, Hartz S, et al. Genetic Risk Can Be Decreased: Quitting Smoking Decreases and Delays Lung Cancer for Smokers With High and Low CHRNA5 Risk Genotypes - A Meta-Analysis. EBioMedicine. 2016; 11: 219-26.

36. Hall FS. Genetic Risk for Lung Cancer and the Benefits of Quitting Smoking. EBioMedicine. 2016; 11: 19-20.

37. Jackson KJ, Marks MJ, Vann RE, Chen X, Gamage TF, Warner JA, et al. Role of alpha5 nicotinic acetylcholine receptors in pharmacological and behavioral effects of nicotine in mice. J Pharmacol Exp Ther. 2010; 334: 137-46.

38. Wang $\mathrm{S}, \mathrm{Hu} \mathrm{Y}$. alpha7 nicotinic acetylcholine receptors in lung cancer. Oncol Lett. 2018; 16: 1375-82.

39. Zhang C, Ding XP, Zhao QN, Yang XJ, An SM, Wang H, et al. Role of alpha7-nicotinic acetylcholine receptor in nicotine-induced invasion and epithelial-to-mesenchymal transition in human non-small cell lung cancer cells. Oncotarget. 2016; 7: 59199-208.

40. Pikor LA, Ramnarine VR, Lam S, Lam WL. Genetic alterations defining NSCLC subtypes and their therapeutic implications. Lung Cancer. 2013; 82: 179-89.

41. Ma G, Ji D, Qu X, Liu S, Yang X, Wang G, et al. Mining and validating the expression pattern and prognostic value of acetylcholine receptors in non-small cell lung cancer. Medicine (Baltimore). 2019; 98: e15555.

42. Chang PM, Yeh YC, Chen TC, Wu YC, Lu PJ, Cheng HC, et al. High expression of CHRNA1 is associated with reduced survival in early stage 
lung adenocarcinoma after complete resection. Ann Surg Oncol. 2013; 20: 3648-54.

43. Hung RJ, McKay JD, Gaborieau V, Boffetta P, Hashibe M, Zaridze D, et al. A susceptibility locus for lung cancer maps to nicotinic acetylcholine receptor subunit genes on 15q25. Nature. 2008; 452: 633-7.

44. Liu P, Vikis HG, Wang D, Lu Y, Wang Y, Schwartz AG, et al. Familial aggregation of common sequence variants on 15q24-25.1 in lung cancer. J Natl Cancer Inst. 2008; 100: 1326-30.

45. Wu C, Hu Z, Yu D, Huang L, Jin G, Liang J, et al. Genetic variants on chromosome $15 \mathrm{q} 25$ associated with lung cancer risk in Chinese populations. Cancer Res. 2009; 69: 5065-72.

46. Saccone NL, Wang JC, Breslau N, Johnson EO, Hatsukami D, Saccone SF, et al. The CHRNA5-CHRNA3-CHRNB4 nicotinic receptor subunit gene cluster affects risk for nicotine dependence in African-Americans and in European-Americans. Cancer Res. 2009; 69: 6848-56.

47. Saccone SF, Hinrichs AL, Saccone NL, Chase GA, Konvicka K, Madden $\mathrm{PA}$, et al. Cholinergic nicotinic receptor genes implicated in a nicotine dependence association study targeting 348 candidate genes with 3713 SNPs. Hum Mol Genet. 2007; 16: 36-49.

48. Pandey N, Pal S, Sharma LK, Guleria R, Mohan A, Srivastava T. SNP rs16969968 as a Strong Predictor of Nicotine Dependence and Lung Cancer Risk in a North Indian Population. Asian Pac J Cancer Prev. 2017; 18: 3073-9.

49. Byun J, Schwartz AG, Lusk C, Wenzlaff AS, de Andrade M, Mandal D, et al. Genome-wide association study of familial lung cancer. Carcinogenesis. 2018; 39: 1135-40.

50. He P, Yang XX, He XQ, Chen J, Li FX, Gu X, et al. CHRNA3 polymorphism modifies lung adenocarcinoma risk in the Chinese Han population. Int J Mol Sci. 2014; 15: 5446-57.

51. Falvella FS, Galvan A, Frullanti E, Spinola M, Calabro E, Carbone A, et al. Transcription deregulation at the $15 \mathrm{q} 25$ locus in association with lung adenocarcinoma risk. Clin Cancer Res. 2009; 15: 1837-42.

52. Pieper MP, Chaudhary NI, Park JE. Acetylcholine-induced proliferation of fibroblasts and myofibroblasts in vitro is inhibited by tiotropium bromide. Life Sci. 2007; 80: 2270-3.

53. Adcock IM, Caramori G, Barnes PJ. Chronic obstructive pulmonary disease and lung cancer: new molecular insights. Respiration. 2011; 81: 265-84.

54. Paleari L, Catassi A, Ciarlo M, Cavalieri Z, Bruzzo C, Servent D, et al. Role of alpha7-nicotinic acetylcholine receptor in human non-small cell lung cancer proliferation. Cell Prolif. 2008; 41: 936-59.

55. Dasgupta P, Rastogi S, Pillai S, Ordonez-Ercan D, Morris M, Haura E, et al. Nicotine induces cell proliferation by beta-arrestin-mediated activation of Src and Rb-Raf-1 pathways. J Clin Invest. 2006; 116: 2208-17.

56. Medjber K, Freidja ML, Grelet S, Lorenzato M, Maouche K, Nawrocki-Raby B, et al. Role of nicotinic acetylcholine receptors in cell proliferation and tumour invasion in broncho-pulmonary carcinomas. Lung Cancer. 2015; 87: 258-64.

57. Al-Wadei HA, Al-Wadei MH, Schuller HM. Cooperative regulation of non-small cell lung carcinoma by nicotinic and beta-adrenergic receptors: a novel target for intervention. PLoS One. 2012; 7: e29915.

58. Zovko A, Viktorsson K, Lewensohn R, Kolosa K, Filipic M, Xing H, et al. APS8, a polymeric alkylpyridinium salt blocks alpha7 nAChR and induces apoptosis in non-small cell lung carcinoma. Mar Drugs. 2013; 11: 2574-94.

59. Grozio A, Paleari L, Catassi A, Servent D, Cilli M, Piccardi F, et al. Natural agents targeting the alpha7-nicotinic-receptor in NSCLC: a promising prospective in anti-cancer drug development. Int J Cancer. 2008; $122: 1911-5$

60. Sheppard BJ, Williams M, Plummer HK, Schuller HM. Activation of voltage-operated Ca2+-channels in human small cell lung carcinoma by the tobacco-specific nitrosamine 4-(methylnitrosamino)-1-(3-pyridyl)-1-butanone. Int J Oncol. 2000; 16: 513-8.

61. Sun X, Ritzenthaler JD, Zhong X, Zheng Y, Roman J, Han S. Nicotine stimulates PPARbeta/delta expression in human lung carcinoma cells through activation of $\mathrm{PI} 3 \mathrm{~K} / \mathrm{mTOR}$ and suppression of AP-2alpha. Cancer Res. 2009; 69: 6445-53.

62. Chernyavsky AI, Shchepotin IB, Grando SA. Mechanisms of growth-promoting and tumor-protecting effects of epithelial nicotinic acetylcholine receptors. Int Immunopharmacol. 2015; 29: 36-44.

63. Zhang C, Yu P, Zhu L, Zhao Q, Lu X, Bo S. Blockade of alpha7 nicotinic acetylcholine receptors inhibit nicotine-induced tumor growth and vimentin expression in non-small cell lung cancer through MEK/ERK signaling way. Oncol Rep. 2017; 38: 3309-18.

64. Mucchietto V, Fasoli F, Pucci S, Moretti M, Benfante R, Maroli A, et al. alpha9- and alpha7-containing receptors mediate the pro-proliferative effects of nicotine in the A549 adenocarcinoma cell line. Br J Pharmacol. 2018; 175: 1957-72.
65. Song P, Sekhon HS, Fu XW, Maier M, Jia Y, Duan J, et al. Activated cholinergic signaling provides a target in squamous cell lung carcinoma. Cancer Res. 2008; 68: 4693-700.

66. Brown KC, Lau JK, Dom AM, Witte TR, Luo H, Crabtree CM, et al. MG624, an alpha7-nAChR antagonist, inhibits angiogenesis via the Egr-1/FGF2 pathway. Angiogenesis. 2012; 15: 99-114.

67. Hung YH, Hung WC. 4-(Methylnitrosamino)-1-(3-pyridyl)-1-butanone (NNK) enhances invasiveness of lung cancer cells by up-regulating contactin-1 via the alpha7 nicotinic acetylcholine receptor/ERK signaling pathway. Chem Biol Interact. 2009; 179: 154-9.

68. Shen J, Xu L, Owonikoko TK, Sun SY, Khuri FR, Curran WJ, et al. NNK promotes migration and invasion of lung cancer cells through activation of c-Src/PKCiota/FAK loop. Cancer Lett. 2012; 318: 106-13.

69. Iskandar AR, Miao B, Li X, Hu KQ, Liu C, Wang XD. beta-Cryptoxanthin Reduced Lung Tumor Multiplicity and Inhibited Lung Cancer Cell Motility by Downregulating Nicotinic Acetylcholine Receptor alpha7 Signaling. Cancer Prev Res (Phila). 2016; 9: 875-86.

70. Egleton RD, Brown KC, Dasgupta P. Nicotinic acetylcholine receptors in cancer: multiple roles in proliferation and inhibition of apoptosis. Trends Pharmacol Sci. 2008; 29: 151-8.

71. Chernyavsky AI, Shchepotin IB, Galitovkiy V, Grando SA. Mechanisms of tumor-promoting activities of nicotine in lung cancer: synergistic effects of cell membrane and mitochondrial nicotinic acetylcholine receptors. BMC Cancer. 2015; 15: 152.

72. Warren GW, Sobus S, Gritz ER. The biological and clinical effects of smoking by patients with cancer and strategies to implement evidence-based tobacco cessation support. Lancet Oncol. 2014; 15: e568-80.

73. Shenker RF, McTyre ER, Ruiz J, Weaver KE, Cramer C, Alphonse-Sullivan NK, et al. The Effects of smoking status and smoking history on patients with brain metastases from lung cancer. Cancer Med. 2017; 6: 944-52.

74. Heeschen C, Weis M, Aicher A, Dimmeler S, Cooke JP. A novel angiogenic pathway mediated by non-neuronal nicotinic acetylcholine receptors. J Clin Invest. 2002; 110: 527-36.

75. Pillai S, Chellappan S. alpha7 nicotinic acetylcholine receptor subunit in angiogenesis and epithelial to mesenchymal transition. Curr Drug Targets. 2012; 13: 671-9.

76. Bregeon F, Xeridat F, Andreotti N, Lepidi H, Delpierre S, Roch A, et al. Activation of nicotinic cholinergic receptors prevents ventilator-induced lung injury in rats. PLoS One. 2011; 6: e22386.

77. Galle-Treger L, Suzuki Y, Patel N, Sankaranarayanan I, Aron JL, Maazi $\mathrm{H}$, et al. Nicotinic acetylcholine receptor agonist attenuates ILC2-dependent airway hyperreactivity. Nat Commun. 2016; 7: 13202.

78. Hajiasgharzadeh K, Sadigh-Eteghad S, Mansoori B, Mokhtarzadeh A, Shanehbandi D, Doustvandi MA, et al. Alpha7 nicotinic acetylcholine receptors in lung inflammation and carcinogenesis: Friends or foes? J Cell Physiol. 2019; 234:14666-79.

79. Ben-Neriah Y, Karin M. Inflammation meets cancer, with NF-kappaB as the matchmaker. Nat Immunol. 2011; 12: 715-23.

80. Parrish WR, Rosas-Ballina M, Gallowitsch-Puerta M, Ochani M, Ochani $\mathrm{K}$, Yang LH, et al. Modulation of TNF release by choline requires alpha7 subunit nicotinic acetylcholine receptor-mediated signaling. Mol Med. 2008; $14: 567-74$

81. de Jonge WJ, van der Zanden EP, The FO, Bijlsma MF, van Westerloo DJ, Bennink RJ, et al. Stimulation of the vagus nerve attenuates macrophage activation by activating the Jak2-STAT3 signaling pathway. Nat Immunol. 2005; 6: 844-51

82. Li Q, Zhou XD, Kolosov VP, Perelman JM. Nicotine reduces TNF-alpha expression through a alpha7 nAChR/MyD88/NF-kB pathway in HBE16 airway epithelial cells. Cell Physiol Biochem. 2011; 27: 605-12.

83. Lu B, Kwan K, Levine YA, Olofsson PS, Yang H, Li J, et al. alpha7 nicotinic acetylcholine receptor signaling inhibits inflammasome activation by preventing mitochondrial DNA release. Mol Med. 2014; 20: 350-8.

84. Wu H, Li L, Su X. Vagus nerve through alpha7 nAChR modulates lung infection and inflammation: models, cells, and signals. Biomed Res Int. 2014; 2014: 283525.

85. Yamada M, Ichinose $M$. The cholinergic anti-inflammatory pathway: an innovative treatment strategy for respiratory diseases and their comorbidities. Curr Opin Pharmacol. 2018; 40: 18-25.

86. Sanner T, Grimsrud TK. Nicotine: Carcinogenicity and Effects on Response to Cancer Treatment - A Review. Front Oncol. 2015; 5 : 196.

87. Grando SA. Connections of nicotine to cancer. Nat Rev Cancer. 2014; 14: 419-29.

88. Hao J, Shi FD, Abdelwahab M, Shi SX, Simard A, Whiteaker P, et al. Nicotinic receptor beta2 determines NK cell-dependent metastasis in a murine model of metastatic lung cancer. PLoS One. 2013; 8: e57495. 
89. Rodriguez RM, Fraga MF. Aging and cancer: are sirtuins the link? Future Oncol. 2010; 6: 905-15.

90. Carafa V, Altucci L, Nebbioso A. Dual Tumor Suppressor and Tumor Promoter Action of Sirtuins in Determining Malignant Phenotype. Front Pharmacol. 2019; 10: 38 .

91. Vaziri H, Dessain SK, Ng Eaton E, Imai SI, Frye RA, Pandita TK, et al. hSIR2(SIRT1) functions as an NAD-dependent p53 deacetylase. Cell. 2001; 107: 149-59.

92. Minagawa S, Araya J, Numata T, Nojiri S, Hara H, Yumino Y, et al. Accelerated epithelial cell senescence in IPF and the inhibitory role of SIRT6 in TGF-beta-induced senescence of human bronchial epithelial cells. Am J Physiol Lung Cell Mol Physiol. 2011; 300: L391-401.

93. Grabowska W, Sikora E, Bielak-Zmijewska A. Sirtuins, a promising target in slowing down the ageing process. Biogerontology. 2017; 18: 447-76.

94. Barnes PJ, Baker J, Donnelly LE. Cellular Senescence as a Mechanism and Target in Chronic Lung Diseases. Am J Respir Crit Care Med. 2019; 200: 556-64.

95. Wang C, Yang W, Dong F, Guo Y, Tan J, Ruan S, et al. The prognostic role of Sirt1 expression in solid malignancies: a meta-analysis. Oncotarget. 2017; 8: 66343-51.

96. Han L, Liang XH, Chen LX, Bao SM, Yan ZQ. SIRT1 is highly expressed in brain metastasis tissues of non-small cell lung cancer (NSCLC) and in positive regulation of NSCLC cell migration. Int J Clin Exp Pathol. 2013; 6: $2357-65$.

97. Jin X, Wei $Y$, Xu F, Zhao M, Dai K, Shen R, et al. SIRT1 promotes formation of breast cancer through modulating Akt activity. J Cancer. 2018; 9: 2012-23.

98. Jung-Hynes B, Nihal M, Zhong W, Ahmad N. Role of sirtuin histone deacetylase SIRT1 in prostate cancer. A target for prostate cancer management via its inhibition? J Biol Chem. 2009; 284: 3823-32.

99. Iskandar AR, Liu C, Smith DE, Hu KQ, Choi SW, Ausman LM, et al. beta-cryptoxanthin restores nicotine-reduced lung SIRT1 to normal levels and inhibits nicotine-promoted lung tumorigenesis and emphysema in A/J mice. Cancer Prev Res (Phila). 2013; 6: 309-20.

100. Wang RH, Sengupta K, Li C, Kim HS, Cao L, Xiao C, et al. Impaired DNA damage response, genome instability, and tumorigenesis in SIRT1 mutant mice. Cancer Cell. 2008; 14: 312-23.

101. Yuan J, Minter-Dykhouse K, Lou Z. A c-Myc-SIRT1 feedback loop regulates cell growth and transformation. J Cell Biol. 2009; 185: 203-11.

102. Ota H, Tokunaga E, Chang K, Hikasa M, Iijima K, Eto $M$, et al. Sirt1 inhibitor, Sirtinol, induces senescence-like growth arrest with attenuated Ras-MAPK signaling in human cancer cells. Oncogene. 2006; 25: 176-85.

103. Zhang Y, Zhang Q, Zeng SX, Hao Q, Lu H. Inauhzin sensitizes p53-dependent cytotoxicity and tumor suppression of chemotherapeutic agents. Neoplasia. 2013; 15: 523-34.

104. Hoffmann G, Breitenbucher F, Schuler M, Ehrenhofer-Murray AE. A novel sirtuin 2 (SIRT2) inhibitor with p53-dependent pro-apoptotic activity in non-small cell lung cancer. J Biol Chem. 2014; 289: 5208-16.

105. Liu G, Su L, Hao X, Zhong N, Zhong D, Singhal S, et al. Salermide up-regulates death receptor 5 expression through the ATF4-ATF3-CHOP axis and leads to apoptosis in human cancer cells. J Cell Mol Med. 2012; 16: $1618-28$.

106. Warren GW, Romano MA, Kudrimoti MR, Randall ME, McGarry RC, Singh AK, et al. Nicotinic modulation of therapeutic response in vitro and in vivo. Int J Cancer. 2012; 131: 2519-27.

107. Vyas S, Zaganjor E, Haigis MC. Mitochondria and Cancer. Cell. 2016; 166: 555-66.

108. Zhang J, Kamdar O, Le W, Rosen GD, Upadhyay D. Nicotine induces resistance to chemotherapy by modulating mitochondrial signaling in lung cancer. Am J Respir Cell Mol Biol. 2009; 40: 135-46.

109. Uspenska K, Lykhmus O, Obolenskaya M, Pons S, Maskos U, Komisarenko S, et al. Mitochondrial Nicotinic Acetylcholine Receptors Support Liver Cells Viability After Partial Hepatectomy. Front Pharmacol. 2018; 9: 626.

110. Jin Z, Gao F, Flagg T, Deng X. Nicotine induces multi-site phosphorylation of Bad in association with suppression of apoptosis. J Biol Chem. 2004; 279: 23837-44.

111. Heusch WL, Maneckjee R. Signalling pathways involved in nicotine regulation of apoptosis of human lung cancer cells. Carcinogenesis. 1998; 19: 551-6.

112. Jia $Y$, Sun $H$, Wu $H$, Zhang $H$, Zhang $X$, Xiao D, et al. Nicotine Inhibits Cisplatin-Induced Apoptosis via Regulating alpha5-nAChR/AKT Signaling in Human Gastric Cancer Cells. PLoS One. 2016; 11: e0149120.

113. Chen RJ, Ho YS, Guo HR, Wang YJ. Long-term nicotine exposure-induced chemoresistance is mediated by activation of Stat3 and downregulation of ERK1/2 via nAChR and beta-adrenoceptors in human bladder cancer cells. Toxicol Sci. 2010; 115: 118-30.
114. Zhao C, Li H, Lin HJ, Yang S, Lin J, Liang G. Feedback Activation of STAT3 as a Cancer Drug-Resistance Mechanism. Trends Pharmacol Sci. 2016; 37: 47-61.

115. Yang SH, Lee TY, Ho CA, Yang CY, Huang WY, Lin YC, et al. Exposure to nicotine-derived nitrosamine ketone and arecoline synergistically facilitates tumor aggressiveness via overexpression of epidermal growth factor receptor and its downstream signaling in head and neck squamous cell carcinoma. PLoS One. 2018; 13: e0201267.

116. Tu SH, Lin YC, Huang CC, Yang PS, Chang HW, Chang $\mathrm{CH}$, et al. Protein phosphatase $\mathrm{Mg} 2+/ \mathrm{Mn} 2+$ dependent $1 \mathrm{~F}$ promotes smoking-induced breast cancer by inactivating phosphorylated-p53-induced signals. Oncotarget. 2016; 7: 77516-31.

117. Li H, Wang S, Takayama K, Harada T, Okamoto I, Iwama E, et al. Nicotine induces resistance to erlotinib via cross-talk between alpha 1 nAChR and EGFR in the non-small cell lung cancer xenograft model. Lung Cancer. 2015; 88: 1-8.

118. Imabayashi T, Uchino J, Osoreda H, Tanimura K, Chihara Y, Tamiya N, et al. Nicotine Induces Resistance to Erlotinib Therapy in Non-Small-Cell Lung Cancer Cells Treated with Serum from Human Patients. Cancers (Basel). 2019; 11: 282.

119. Gong J, Wang H, Lou W, Wang G, Tao H, Wen H, et al. Associations of sirtuins with clinicopathological parameters and prognosis in non-small cell lung cancer. Cancer Manag Res. 2018; 10: 3341-56.

120. Azuma Y, Yokobori T, Mogi A, Altan B, Yajima T, Kosaka T, et al. SIRT6 expression is associated with poor prognosis and chemosensitivity in patients with non-small cell lung cancer. J Surg Oncol. 2015; 112: 231-7.

121. Barr J, Sharma CS, Sarkar S, Wise K, Dong L, Periyakaruppan A, et al. Nicotine induces oxidative stress and activates nuclear transcription factor kappa B in rat mesencephalic cells. Mol Cell Biochem. 2007; 297: 93-9.

122. German NJ, Haigis MC. Sirtuins and the Metabolic Hurdles in Cancer. Curr Biol. 2015; 25: R569-83.

123. Kulkarni SR, Donepudi AC, Xu J, Wei W, Cheng QC, Driscoll MV, et al. Fasting induces nuclear factor E2-related factor 2 and ATP-binding Cassette transporters via protein kinase A and Sirtuin-1 in mouse and human. Antioxid Redox Signal. 2014; 20: 15-30.

124. Torrens-Mas M, Pons DG, Sastre-Serra J, Oliver J, Roca P. SIRT3 Silencing Sensitizes Breast Cancer Cells to Cytotoxic Treatments Through an Increment in ROS Production. J Cell Biochem. 2017; 118: 397-406.

125. Jeong SM, Hwang S, Seong RH. SIRT4 regulates cancer cell survival and growth after stress. Biochem Biophys Res Commun. 2016; 470: 251-6.

126. Lin ZF, Xu HB, Wang JY, Lin Q, Ruan Z, Liu FB, et al. SIRT5 desuccinylates and activates SOD1 to eliminate ROS. Biochem Biophys Res Commun. 2013; 441: 191-5.

127. Lu W, Zuo Y, Feng Y, Zhang M. SIRT5 facilitates cancer cell growth and drug resistance in non-small cell lung cancer. Tumour Biol. 2014; 35: 10699-705.

128. Park GJ, Kim YS, Kang KL, Bae SJ, Baek HS, Auh QS, et al. Effects of sirtuin 1 activation on nicotine and lipopolysaccharide-induced cytotoxicity and inflammatory cytokine production in human gingival fibroblasts. J Periodontal Res. 2013; 48: 483-92.

129. Lu J, Zhang M, Huang Z, Sun S, Zhang Y, Zhang L, et al. SIRT1 in $\mathrm{B}$ [a]P-induced lung tumorigenesis. Oncotarget. 2015; 6: 27113-29.

130. Hwang JW, Chung S, Sundar IK, Yao H, Arunachalam G, McBurney $\mathrm{MW}$, et al. Cigarette smoke-induced autophagy is regulated by SIRT1-PARP-1-dependent mechanism: implication in pathogenesis of COPD. Arch Biochem Biophys. 2010; 500: 203-9.

131. Li DJ, Huang F, Ni M, Fu H, Zhang LS, Shen FM. alpha7 Nicotinic Acetylcholine Receptor Relieves Angiotensin II-Induced Senescence in Vascular Smooth Muscle Cells by Raising Nicotinamide Adenine Dinucleotide-Dependent SIRT1 Activity. Arterioscler Thromb Vasc Biol. 2016; 36: 1566-76.

132. Michan S, Sinclair D. Sirtuins in mammals: insights into their biological function. Biochem J. 2007; 404: 1-13.

133. Haigis MC, Guarente LP. Mammalian sirtuins--emerging roles in physiology, aging, and calorie restriction. Genes Dev. 2006; 20: 2913-21.

134. Yamamoto H, Schoonjans K, Auwerx J. Sirtuin functions in health and disease. Mol Endocrinol. 2007; 21: 1745-55.

135. Yang X, Yang Y, Gan R, Zhao L, Li W, Zhou H, et al. Down-regulation of mir-221 and mir-222 restrain prostate cancer cell proliferation and migration that is partly mediated by activation of SIRT1. PLoS One. 2014; 9: e98833.

136. Zhang T, Rong N, Chen J, Zou C, Jing H, Zhu X, et al. SIRT1 expression is associated with the chemotherapy response and prognosis of patients with advanced NSCLC. PLoS One. 2013; 8: e79162.

137. Chen $\mathrm{G}$, Zhang $\mathrm{B}$, $\mathrm{Xu} \mathrm{H}$, Sun $\mathrm{Y}$, Shi $\mathrm{Y}$, Luo $\mathrm{Y}$, et al. Suppression of Sirt1 sensitizes lung cancer cells to WEE1 inhibitor MK-1775-induced DNA damage and apoptosis. Oncogene. 2017; 36: 6863-72. 
138. Yi J, Luo J. SIRT1 and p53, effect on cancer, senescence and beyond. Biochim Biophys Acta. 2010; 1804: 1684-9.

139. Olmos Y, Sanchez-Gomez FJ, Wild B, Garcia-Quintans N, Cabezudo S, Lamas S, et al. SirT1 regulation of antioxidant genes is dependent on the formation of a FoxO3a/PGC-1alpha complex. Antioxid Redox Signal. 2013; 19: 1507-21.

140. Voelter-Mahlknecht S, Mahlknecht U. The sirtuins in the pathogenesis of cancer. Clin Epigenetics. 2010; 1: 71-83.

141. Mvunta DH, Miyamoto T, Asaka R, Yamada Y, Ando H, Higuchi S, et al. SIRT1 Regulates the Chemoresistance and Invasiveness of Ovarian Carcinoma Cells. Transl Oncol. 2017; 10: 621-31.

142. Xiong Y, Wang M, Zhao J, Wang L, Li X, Zhang Z, et al. SIRT3 is correlated with the malignancy of non-small cell lung cancer. Int J Oncol. 2017; 50: 903-10.

143. Li DJ, Tong J, Zeng FY, Guo M, Li YH, Wang H, et al. Nicotinic ACh receptor alpha7 inhibits PDGF-induced migration of vascular smooth muscle cells by activating mitochondrial deacetylase sirtuin 3 . Br J Pharmacol. 2018 (online)

144. Ansari A, Rahman MS, Saha SK, Saikot FK, Deep A, Kim KH. Function of the SIRT3 mitochondrial deacetylase in cellular physiology, cancer, and neurodegenerative disease. Aging Cell. 2017; 16: 4-16.

145. Zhang L, Ren X, Cheng Y, Huber-Keener K, Liu X, Zhang Y, et al. Identification of Sirtuin 3, a mitochondrial protein deacetylase, as a new contributor to tamoxifen resistance in breast cancer cells. Biochem Pharmacol. 2013; 86: 726-33.

146. Xiong Y, Wang L, Wang S, Wang M, Zhao J, Zhang Z, et al. SIRT3 deacetylates and promotes degradation of P53 in PTEN-defective non-small cell lung cancer. J Cancer Res Clin Oncol. 2018; 144: 189-98.

147. Saunders LR, Verdin E. Sirtuins: critical regulators at the crossroads between cancer and aging. Oncogene. 2007; 26: 5489-504.

148. Carnevale I, Pellegrini L, D'Aquila P, Saladini S, Lococo E, Polletta L, et al. SIRT1-SIRT3 Axis Regulates Cellular Response to Oxidative Stress and Etoposide. J Cell Physiol. 2017; 232: 1835-44.

149. Engler A, Niederer F, Klein K, Gay RE, Kyburz D, Camici GG, et al. SIRT6 regulates the cigarette smoke-induced signalling in rheumatoid arthritis synovial fibroblasts. J Mol Med (Berl). 2014; 92: 757-67.

150. Kim EJ, Juhnn YS. Cyclic AMP signaling reduces sirtuin 6 expression in non-small cell lung cancer cells by promoting ubiquitin-proteasomal degradation via inhibition of the Raf-MEK-ERK (Raf/mitogen-activated extracellular signal-regulated kinase/extracellular signal-regulated kinase) pathway. J Biol Chem. 2015; 290: 9604-13.

151. Jiang Y, Han Z, Wang Y, Hao W. Depletion of SIRT7 sensitizes human non-small cell lung cancer cells to gemcitabine therapy by inhibiting autophagy. Biochem Biophys Res Commun. 2018; 506: 266-71.

152. Shi H, Ji Y, Zhang D, Liu Y, Fang P. MicroRNA-3666-induced suppression of SIRT7 inhibits the growth of non-small cell lung cancer cells. Oncol Rep. 2016; 36: 3051-7.

153. Li Z, Xie QR, Chen Z, Lu S, Xia W. Regulation of SIRT2 levels for human non-small cell lung cancer therapy. Lung Cancer. 2013; 82: 9-15.

154. Fu L, Dong Q, He J, Wang X, Xing J, Wang E, et al. SIRT4 inhibits malignancy progression of NSCLCs, through mitochondrial dynamics mediated by the ERK-Drp1 pathway. Oncogene. 2017; 36: 2724-36.

155. Wang C, Niu W, Chen H, Shi N, He D, Zhang M, et al. Nicotine suppresses apoptosis by regulating alpha7nAChR/Prx1 axis in oral precancerous lesions. Oncotarget. 2017; 8: 75065-75.

156. Marrero MB, Bencherif M. Convergence of alpha 7 nicotinic acetylcholine receptor-activated pathways for anti-apoptosis and anti-inflammation: central role for JAK2 activation of STAT3 and NF-kappaB. Brain Res. 2009; 1256: 1-7.

157. Pillai S, Rizwani W, Li X, Rawal B, Nair S, Schell MJ, et al. ID1 facilitates the growth and metastasis of non-small cell lung cancer in response to nicotinic acetylcholine receptor and epidermal growth factor receptor signaling. Mol Cell Biol. 2011; 31: 3052-67.

158. Lykhmus O, Gergalova G, Koval L, Zhmak M, Komisarenko S, Skok M. Mitochondria express several nicotinic acetylcholine receptor subtypes to control various pathways of apoptosis induction. Int J Biochem Cell Biol. 2014; 53: 246-52

159. Chernyavsky A, Chen Y, Wang PH, Grando SA. Pemphigus vulgaris antibodies target the mitochondrial nicotinic acetylcholine receptors that protect keratinocytes from apoptolysis. Int Immunopharmacol. 2015; 29: 76-80.

160. Peck B, Chen CY, Ho KK, Di Fruscia P, Myatt SS, Coombes RC, et al. SIRT inhibitors induce cell death and p53 acetylation through targeting both SIRT1 and SIRT2. Mol Cancer Ther. 2010; 9: 844-55.

161. Jin KL, Park JY, Noh EJ, Hoe KL, Lee JH, Kim JH, et al. The effect of combined treatment with cisplatin and histone deacetylase inhibitors on HeLa cells. J Gynecol Oncol. 2010; 21: 262-8.

162. Islam S, Abiko Y, Uehara O, Chiba I. Sirtuin 1 and oral cancer. Oncol Lett. 2019; 17: 729-38.
163. Jeung YJ, Kim HG, Ahn J, Lee HJ, Lee SB, Won M, et al. Shikonin induces apoptosis of lung cancer cells via activation of FOXO3a/EGR1/SIRT1 signaling antagonized by p300. Biochim Biophys Acta. 2016; 1863: 2584-93.

164. Jin YD, Ren $Y, W u$ MW, Chen P, Lu J. Effect of shikonin on multidrug resistance in HepG2: The role of SIRT1. Pharm Biol. 2015; 53: 1016-21.

165. Gupta RA, Shah N, Wang KC, Kim J, Horlings HM, Wong DJ, et al. Long non-coding RNA HOTAIR reprograms chromatin state to promote cancer metastasis. Nature. 2010; 464: 1071-6.

166. Ponting CP, Oliver PL, Reik W. Evolution and functions of long noncoding RNAs. Cell. 2009; 136: 629-41.

167. Guttman M, Donaghey J, Carey BW, Garber M, Grenier JK, Munson G, et al. lincRNAs act in the circuitry controlling pluripotency and differentiation. Nature. 2011; 477: 295-300.

168. Ji P, Diederichs S, Wang W, Boing S, Metzger R, Schneider PM, et al. MALAT-1, a novel noncoding RNA, and thymosin beta4 predict metastasis and survival in early-stage non-small cell lung cancer. Oncogene. 2003; 22: 8031-41.

169. Thai P, Statt S, Chen CH, Liang E, Campbell C, Wu R. Characterization of a novel long noncoding RNA, SCAL1, induced by cigarette smoke and elevated in lung cancer cell lines. Am J Respir Cell Mol Biol. 2013; 49: 204-11.

170. Tani H, Torimura M, Akimitsu N. The RNA degradation pathway regulates the function of GAS5 a non-coding RNA in mammalian cells. PLoS One. 2013; 8: e55684.

171. Tani H, Torimura M. Development of cytotoxicity-sensitive human cells using overexpression of long non-coding RNAs. J Biosci Bioeng. 2015; 119: 604-8.

172. Liu Y, Luo F, Xu Y, Wang B, Zhao Y, Xu W, et al. Epithelial-mesenchymal transition and cancer stem cells, mediated by a long non-coding RNA, HOTAIR, are involved in cell malignant transformation induced by cigarette smoke extract. Toxicol Appl Pharmacol. 2015; 282: 9-19.

173. Lane RE, Korbie D, Hill MM, Trau M. Extracellular vesicles as circulating cancer biomarkers: opportunities and challenges. Clin Transl Med. 2018; 7: 14

174. Yuan T, Huang X, Woodcock M, Du M, Dittmar R, Wang Y, et al. Plasma extracellular RNA profiles in healthy and cancer patients. Sci Rep. 2016; 6: 19413.

175. Qu L, Ding J, Chen C, Wu ZJ, Liu B, Gao Y, et al. Exosome-Transmitted lncARSR Promotes Sunitinib Resistance in Renal Cancer by Acting as a Competing Endogenous RNA. Cancer Cell. 2016; 29: 653-68.

176. Xu CG, Yang MF, Ren YQ, Wu CH, Wang LQ. Exosomes mediated transfer of lncRNA UCA1 results in increased tamoxifen resistance in breast cancer cells. Eur Rev Med Pharmacol Sci. 2016; 20: 4362-8.

177. Lian B, Yang D, Liu Y, Shi G, Li J, Yan X, et al. miR-128 Targets the SIRT1/ROS/DR5 Pathway to Sensitize Colorectal Cancer to TRAIL-Induced Apoptosis. Cell Physiol Biochem. 2018; 49: 2151-62.

178. Shi L, Tang X, Qian M, Liu Z, Meng F, Fu L, et al. A SIRT1-centered circuitry regulates breast cancer stemness and metastasis. Oncogene. 2018; 37: 6299-315.

179. Xia X, Zhou X. Knockdown of SIRT1 inhibits proliferation and promotes apoptosis of paclitaxel-resistant human cervical cancer cells. Cell Mol Biol (Noisy-le-grand). 2018; 64: 36-41.

180. Ma L, Cheng Q. Inhibiting 6-phosphogluconate dehydrogenase reverses doxorubicin resistance in anaplastic thyroid cancer via inhibiting NADPH-dependent metabolic reprogramming. Biochem Biophys Res Commun. 2018; 498: 912-7.

181. Chen H, Zhang W, Cheng X, Guo L, Xie S, Ma Y, et al. beta2-AR activation induces chemoresistance by modulating p53 acetylation through upregulating Sirt1 in cervical cancer cells. Cancer Sci. 2017; 108: 1310-7.

182. Zhang L, Guo X, Zhang D, Fan Y, Qin L, Dong S, et al. Upregulated miR-132 in Lgr5(+) gastric cancer stem cell-like cells contributes to cisplatin-resistance via SIRT1/CREB/ABCG2 signaling pathway. Mol Carcinog. 2017; 56: 2022-34

183. Xiong H, Ni Z, He J, Jiang S, Li X, He J, et al. LncRNA HULC triggers autophagy via stabilizing Sirt1 and attenuates the chemosensitivity of HCC cells. Oncogene. 2017; 36: 3528-40.

184. Wang X, Yang B, Ma B. The UCA1/miR-204/Sirt1 axis modulates docetaxel sensitivity of prostate cancer cells. Cancer Chemother Pharmacol. 2016; 78: 1025-31.

185. Li K, Ying M, Feng D, Du J, Chen S, Dan B, et al. Brachyury promotes tamoxifen resistance in breast cancer by targeting SIRT1. Biomed Pharmacother. 2016; 84: 28-33.

186. Lin MH, Lee YH, Cheng HL, Chen HY, Jhuang FH, Chueh PJ. Capsaicin Inhibits Multiple Bladder Cancer Cell Phenotypes by Inhibiting Tumor-Associated NADH Oxidase (tNOX) and Sirtuin1 (SIRT1). Molecules. 2016; 21: 849. 
187. Li L, Ye S, Yang M, Yu W, Fan Z, Zhang H, et al. SIRT1 downregulation enhances chemosensitivity and survival of adult T-cell leukemia-lymphoma cells by reducing DNA double-strand repair. Oncol Rep. 2015; 34: 2935-42.

188. Asaka R, Miyamoto T, Yamada Y, Ando H, Mvunta DH, Kobara H, et al. Sirtuin 1 promotes the growth and cisplatin resistance of endometrial carcinoma cells: a novel therapeutic target. Lab Invest. 2015; 95: 1363-73.

189. Kim HB, Lee SH, Um JH, Kim MJ, Hyun SK, Gong EJ, et al. Sensitization of chemo-resistant human chronic myeloid leukemia stem-like cells to Hsp90 inhibitor by SIRT1 inhibition. Int J Biol Sci. 2015; 11: 923-34.

190. Cao B, Shi Q, Wang W. Higher expression of SIRT1 induced resistance of esophageal squamous cell carcinoma cells to cisplatin. J Thorac Dis. 2015; 7: 711-9.

191. Liu Y, Li X, Zhu S, Zhang JG, Yang M, Qin Q, et al. Ectopic expression of miR-494 inhibited the proliferation, invasion and chemoresistance of pancreatic cancer by regulating SIRT1 and c-Myc. Gene Ther. 2015; 22: 729-38.

192. Vellinga TT, Borovski T, de Boer VC, Fatrai S, van Schelven S, Trumpi K, et al. SIRT1/PGC1alpha-Dependent Increase in Oxidative Phosphorylation Supports Chemotherapy Resistance of Colon Cancer. Clin Cancer Res. 2015; 21: 2870-9.

193. Wang W, Zhang J, Li Y, Yang X, He Y, Li T, et al. Divalproex sodium enhances the anti-leukemic effects of imatinib in chronic myeloid leukemia cells partly through SIRT1. Cancer Lett. 2015; 356: 791-9.

194. Li L, Osdal T, Ho Y, Chun S, McDonald T, Agarwal P, et al. SIRT1 activation by a c-MYC oncogenic network promotes the maintenance and drug resistance of human FLT3-ITD acute myeloid leukemia stem cells. Cell Stem Cell. 2014; 15: 431-46.

195. Kweon KH, Lee CR, Jung SJ, Ban EJ, Kang SW, Jeong JJ, et al. Sirt1 induction confers resistance to etoposide-induced genotoxic apoptosis in thyroid cancers. Int J Oncol. 2014; 45: 2065-75.

196. Do MT, Kim HG, Choi JH, Jeong HG. Metformin induces microRNA-34a to downregulate the Sirt1/Pgc-1alpha/Nrf2 pathway, leading to increased susceptibility of wild-type p53 cancer cells to oxidative stress and therapeutic agents. Free Radic Biol Med. 2014; 74: 21-34.

197. Wang Z, Liu Z, Wu X, Chu S, Wang J, Yuan H, et al. ATRA-induced cellular differentiation and CD38 expression inhibits acquisition of BCR-ABL mutations for CML acquired resistance. PLoS Genet. 2014; 10: e1004414.

198. Wei R, He D, Zhang X. Role of SIRT2 in Regulation of Stemness of Cancer Stem-Like Cells in Renal Cell Carcinoma. Cell Physiol Biochem. 2018; 49: 2348-57.

199. Xu H, Li Y, Chen L, Wang C, Wang Q, Zhang H, et al. SIRT2 mediates multidrug resistance in acute myelogenous leukemia cells via ERK1/2 signaling pathway. Int J Oncol. 2016; 48: 613-23.

200. Karwaciak I, Gorzkiewicz M, Ryba K, Dastych J, Pulaski L, Ratajewski M. AC-93253 triggers the downregulation of melanoma progression markers and the inhibition of melanoma cell proliferation. Chem Biol Interact. 2015; 236: 9-18.

201. Shiozawa K, Shuting J, Yoshioka Y, Ochiya T, Kondo T. Extracellular vesicle-encapsulated microRNA-761 enhances pazopanib resistance in synovial sarcoma. Biochem Biophys Res Commun. 2018; 495: 1322-7.

202. Casadei Gardini A, Faloppi L, De Matteis S, Foschi FG, Silvestris N, Tovoli F, et al. Metformin and insulin impact on clinical outcome in patients with advanced hepatocellular carcinoma receiving sorafenib: Validation study and biological rationale. Eur J Cancer. 2017; 86: 106-14.

203. Cheng Y, Dai C, Zhang J. SIRT3-SOD2-ROS pathway is involved in linalool-induced glioma cell apoptotic death. Acta Biochim Pol. 2017; 64: 343-50.

204. Huang G, Cheng J, Yu F, Liu X, Yuan C, Liu C, et al. Clinical and therapeutic significance of sirtuin-4 expression in colorectal cancer. Oncol Rep. 2016; 35: 2801-10.

205. Hu JQ, Deng F, Hu XP, Zhang W, Zeng XC, Tian XF. Histone deacetylase SIRT6 regulates chemosensitivity in liver cancer cells via modulation of FOXO3 activity. Oncol Rep. 2018; 40: 3635-44.

206. Dai PC, Liu DL, Zhang L, Ye J, Wang Q, Zhang HW, et al. Astragaloside IV sensitizes non-small cell lung cancer cells to gefitinib potentially via regulation of SIRT6. Tumour Biol. 2017; 39: 1010428317697555.

207. Sociali G, Galeno L, Parenti MD, Grozio A, Bauer I, Passalacqua M, et al. Quinazolinedione SIRT6 inhibitors sensitize cancer cells to chemotherapeutics. Eur J Med Chem. 2015; 102: 530-9.

208. Thirumurthi U, Shen J, Xia W, LaBaff AM, Wei Y, Li CW, et al MDM2-mediated degradation of SIRT6 phosphorylated by AKT1 promotes tumorigenesis and trastuzumab resistance in breast cancer. Sci Signal. 2014; 7: ra71.

209. Aljada A, Saleh AM, Al Suwaidan S. Modulation of insulin/IGFs pathways by sirtuin-7 inhibition in drug-induced chemoreistance. Diagn Pathol. 2014; 9: 94 